\title{
Sensitivity of GNSS-R Spaceborne Observations to Soil Moisture and Vegetation
}

\author{
Adriano Camps, Hyuk Park, Miriam Pablos, Giuseppe Foti, Christine P. Gommenginger, \\ Pang-Wei Liu, and Jasmeet Judge
}

\begin{abstract}
Global navigation satellite systems-reflectometry (GNSS-R) is an emerging remote sensing technique that makes use of navigation signals as signals of opportunity in a multistatic radar configuration, with as many transmitters as navigation satellites are in view. GNSS-R sensitivity to soil moisture has already been proven from ground-based and airborne experiments, but studies using space-borne data are still preliminary due to the limited amount of data, collocation, footprint heterogeneity, etc. This study presents a sensitivity study of TechDemoSat-1 GNSS-R data to soil moisture over different types of surfaces (i.e., vegetation covers) and for a wide range of soil moisture and normalized difference vegetation index (NDVI) values. Despite the scattering in the data, which can be largely attributed to the delay-Doppler maps peak variance, the temporal and spatial (footprint size) collocation mismatch with the SMOS soil moisture, and MODIS NDVI vegetation data, and land use data, experimental results for low NDVI values show a large sensitivity to soil moisture and a relatively good Pearson correlation coefficient. As the vegetation cover increases (NDVI increases) the reflectivity, the sensitivity to soil moisture and the Pearson correlation coefficient decreases, but it is still significant.
\end{abstract}

Index Terms-Global navigation satellite systems-reflectometry (GNSS-R), land use, MODIS, normalized difference vegetation index (NDVI), SMOS, soil moisture (SM), TechDemoSat-1 (TDS-1).

\section{INTRODUCTION}

$\mathbf{T}$ HE use of global positioning system (GPS) signals as signals of opportunity to perform scatterometry was first proposed in 1988 [1]. Three years later, in 1991, there was the first evidence that GPS navigation signals could be collected and tracked after being scattered on the sea surface, when a French aircraft was testing a GPS receiver [2]. In 1993, the concept of interferometric GNSS-R, in which the direct and scattered signals are cross-correlated to take advantage of the large bandwidth signals, was proposed by ESA for mesoscale ocean altimetry [3]. In 1996, an analysis of the properties of the scattered signal

Manuscript received March 31, 2016; revised June 1, 2016; accepted June 25, 2016. Date of publication July 26, 2016; date of current version October 14, 2016. (Corresponding author: Adriano Camps.)

A. Camps, H. Park, and M. Pablos are with the Department of Signal Theory and Communications, Universitat Politècnica de Catalunya, Barcelona E08034, Spain, and also with the Institut d'Estudis Espacials de Catalunya, Barcelona 08007, Spain (e-mail: camps@ @tsc.upc.edu; park.hyuk@ tsc.upc.edu; miriam.pablos@tsc.upc.edu).

G. Foti and C. P. Gommenginger are with the National Oceanography Centre, University of Southampton, Southampton SO17 1BJ, U.K. (e-mail: g.foti@noc.ac.uk; cg1@noc.ac.uk).

P.-W. Liu and J. Judge are with the Department of Agricultural and Biological Engineering, University of Florida, Gainsville, FL 32608 USA (e-mail: bonwei@ufl.edu; jasmeet@ufl.edu).

Color versions of one or more of the figures in this paper are available online at http://ieeexplore.ieee.org

Digital Object Identifier 10.1109/JSTARS.2016.2588467 when cross-correlated with a replica of the direct signal was performed [4], a technique known today as conventional GNSS-R, and in 1997, the first GPS reflected signals were collected from an aircraft using NASA's delay mapping receiver [5]. The first GPS-R data from space were found in fragments of SIR-C data without radar returns [6]. The first dedicated space-borne GPS reflectometer was a secondary payload on board the UK-DMC satellite (launched in September 2003 [7]) consisting of a L1 C/A data logger with an 11.8-dB antenna gain. The UK-DMC GPS-R experiment demonstrated the feasibility of GPS reflectometry from ocean, ice, and land surfaces. More recently, in July 2014, the UK TechDemoSat-1 mission (TDS-1) was successfully launched [8] carrying an improved secondary L1 C/A Code GNSS-R payload (SGR-ReSI), with options for Galileo E1, GPS L2C, Glonass L1, GPS L5, Galileo E5, and on-board data processing [9].

Today, with the advent of other satellite navigation systems either global (GNSS such as GPS, Glonass, Galileo, and Beidou), regional (RNSS such as IRNSS and QZSS), or satellite-based augmentation systems (SBAS such as EGNOS, WAAS, MSAS), the number of transmitting satellites is rapidly increasing, providing a large number of simultaneous observations.

From the originally proposed applications (wind speed [1] and altimetry [3]), many others have been developed including wind speed and direction measurements, ice altimetry, soil moisture, vegetation height and biomass, snow depth (see, for example, [10] for an in depth review, and in particular [11]-[13] for previous studies on the dependence with soil moisture (SM) of different GNSS-R observables, namely the interference pattern technique and scatterometry observations).

This study explores the sensitivity of TDS-1 GNSS-R data to soil moisture, taking into account different vegetation covers, and their condition, parameterized as a function of the normalized difference vegetation index (NDVI). It is organized as follows: Section II describes the methodology, the data acquired, the data processing, and collocation, and compares them with the ones used in a recently published work [14]. Section III presents the results obtained as a function of the land use, the SM and the NDVI, and discusses them. Finally, Section IV summarizes the main conclusions.

\section{Methodology}

TDS-1 GNSS-R payload measures the reflected GNSS signals only. Since no reference (direct signal) is measured, GNSS$\mathrm{R}$ data are uncalibrated. Therefore, in this study, following the same procedure as in [15] and [16], the data processing is performed using the variations of the signal-to-noise ratio (SNR) 


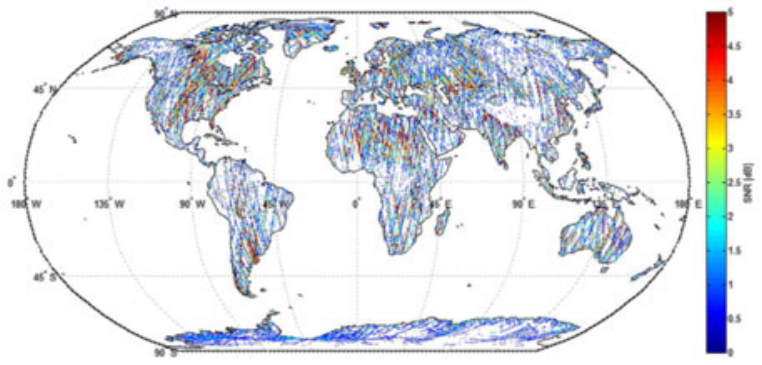

Fig. 1. TDS-1 GNSS-R SNR map [dB] over land (scale truncated to $5 \mathrm{~dB}$, antenna gain $\geq 10 \mathrm{~dB}$ ).

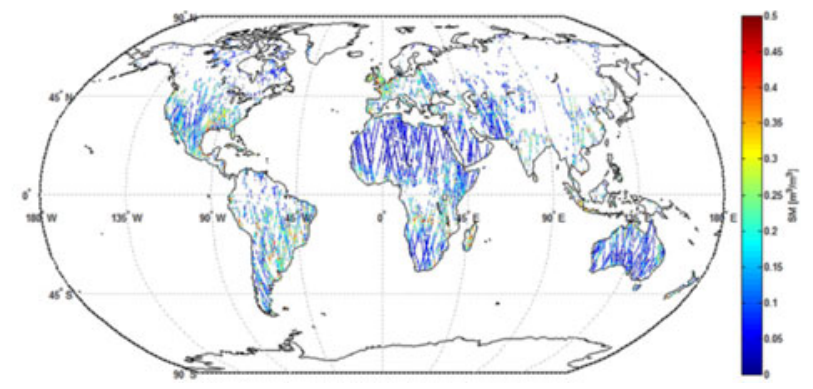

Fig. 2. Available SMOS L3 SM data [17] collocated with TDS-1 GNSS-R data.

of the delay-Doppler maps (DDMs) computed using 1-ms coherent integration time, followed by 1000 incoherent averages (total integration time $=1 \mathrm{~s}$ ), as the ratio of:

1) the uncalibrated signal power computed as the average power over a $1.5 \mathrm{kHz} \times 1$ chip window centered around the peak position of the DDM, and

2) the uncalibrated noise power computed as the average power over a $10 \mathrm{kHz} \times 1$ chip window in the signal-free area of the DDM, before the leading edge of the waveform after compensation of the antenna gain versus the gain in the boresight direction, as in [16]. ${ }^{1}$

Fig. 1 shows the collected available data from September 1st, 2014 to February 5th, 2015, filtered for antenna gains larger than $10 \mathrm{~dB}$, which correspond to near-nadir $\left(\theta_{\mathrm{i}}<15^{\circ}\right)$ reflections collected through the antenna half-power beamwidth $\left(\Delta \theta_{-3 \mathrm{~dB}}=30^{\circ}\right)$, and, therefore, the variation of the reflection coefficient due to variations of the incidence angle is negligible. The dataset analyzed consists of a total of 515540 GNSS-R observations.

In order to analyze the TDS-1 dataset, the following datasets have been collocated:

1) SM data from SMOS level 3 [17] (see Fig. 2), ${ }^{2}$

2) NDVI data from MODIS [18] (see Fig. 3), and for proper data interpretation, data have also been separated using the most recently available (2011) global land cover map

\footnotetext{
${ }^{1}$ In [11], the reflected power is computed as subtracting an average noise floor, the antenna pattern gain is also compensated, and the different range variations are accounted for to be able to account for a larger range of incidence angles, resulting in a normalized observable similar to the one used in this paper.

${ }^{2}$ The SMOS level 2 v620 operational processor was used in the generation of the level 3 products [https://earth.esa.int/documents/10174/ 1854503/SMOS_L2SMv620_release_note].
}

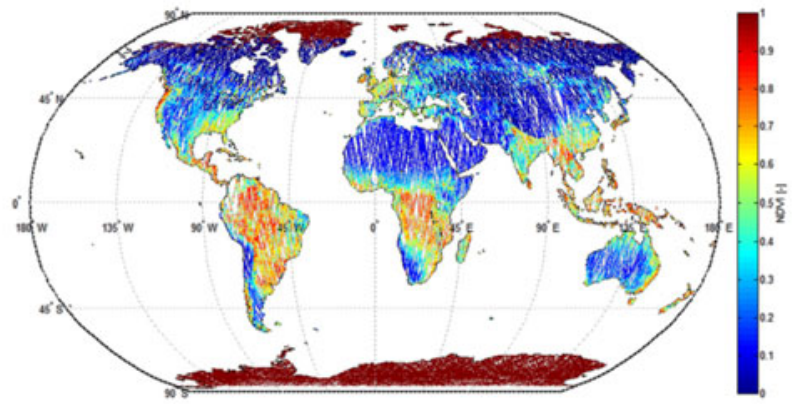

Fig. 3. MODIS NDVI [18] collocated with TDS-1 GNSS-R data.

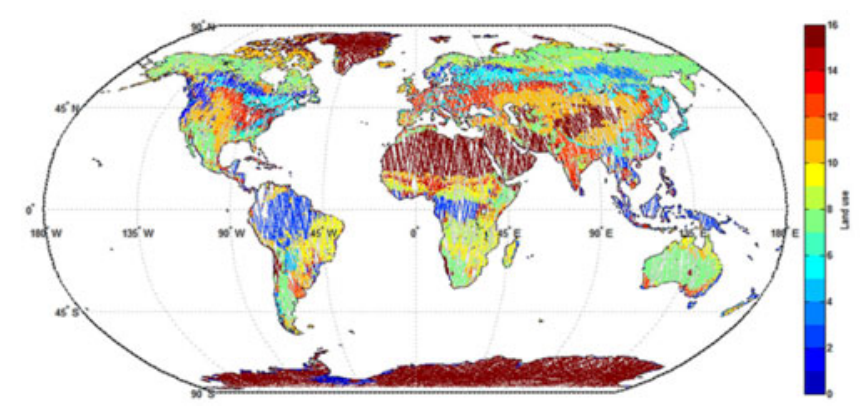

Fig. 4. MODIS land cover map [19] collocated with TDS-1 GNSS-R data. Classes are described in the text.

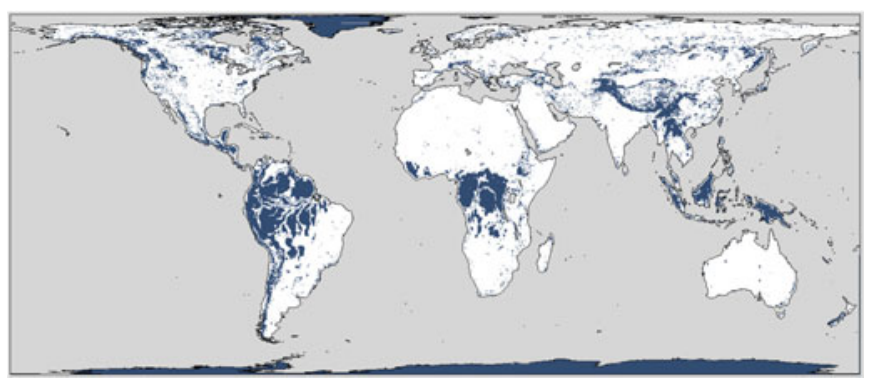

Fig. 5. Regions (marked in blue) where SM accuracy requirements $\left(0.04 \mathrm{~m}^{3} / \mathrm{m}^{3}\right)$ cannot be met.

derived from MODIS [19] (see Fig. 4), including the following classes: 0) water, 1) evergreen needleleaf forest, 2) evergreen broadleaf forest, 3) deciduous needleleaf forest, 4) deciduous broadleaf forest, 5) mixed forest, 6) closed shrub land, 7) open shrubland, 8) woody savanna, 9) savanna, 10) grassland, 11) permanent wetlands, 12) croplands, 13) urban and built up, 14) cropland/natural vegetation, 15) permanent snow and ice, and 16) barren or sparsely vegetated.

It is important to note that the SM accuracy threshold $\left(0.04 \mathrm{~m}^{3} / \mathrm{m}^{3}\right)$ can only be met over the land areas marked in blue in Fig. 5, which exclude frozen global land regions, regions with high topography (standard deviation of elevation larger than $300 \mathrm{~m}$ ), open water (fraction larger than 10\%), urban areas (larger than 50\%), densely vegetated regions with average vegetation water content (VWC) larger than $5 \mathrm{~kg} / \mathrm{m}^{2}$, where the sensitivity of the microwave signal to SM decreases significantly, or areas contaminated by radio-frequency interference. In all these areas, SMOS SM retrievals fail or are not even attempted, 


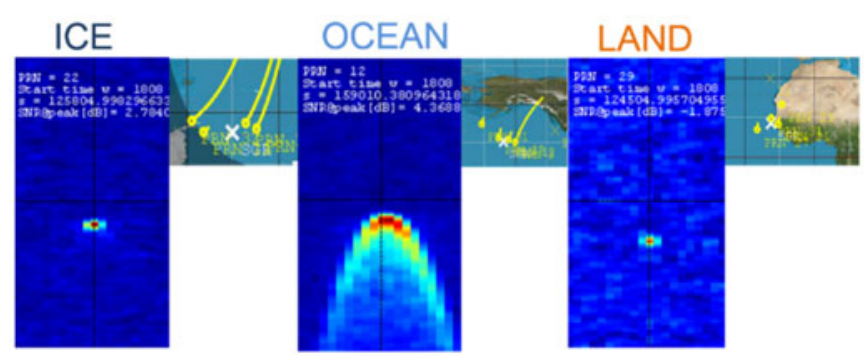

Fig. 6. Sample DDM over ice, ocean and land, as measured by TDS-1 [http://www.merrbys.co.uk/]. Over ice there is and almost perfect specular reflection, showing a strong coherent component. Over the ocean the scattering comes from a large area, the coherent component has almost vanished, and the incoherent component dominates. Over land the scattering comes from a reduced area around the specular reflection point, there is a non-negligible coherent component, but the incoherent component is also present.

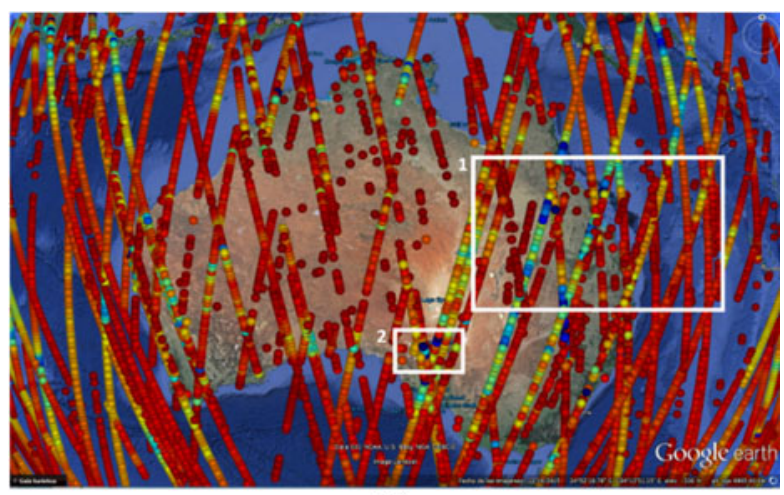

(a)

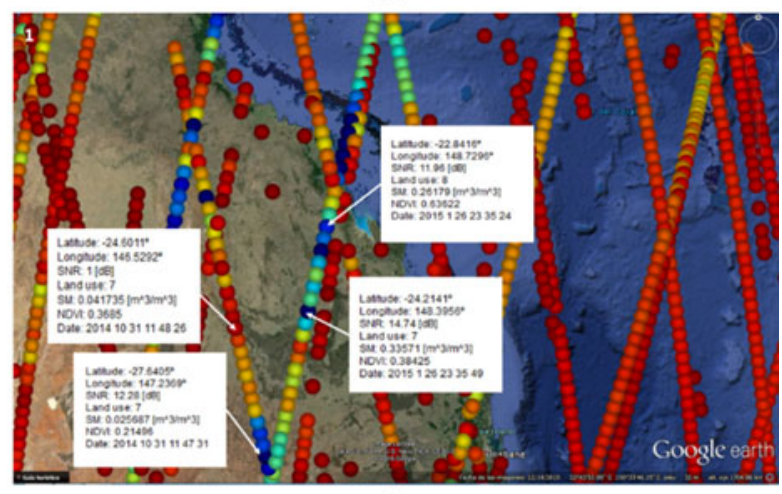

(b)

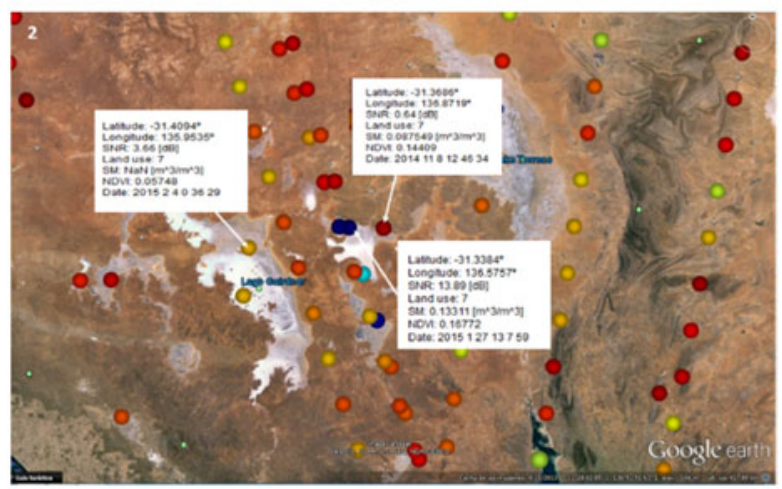

(c)

Fig. 7. Selected target areas over Australia.

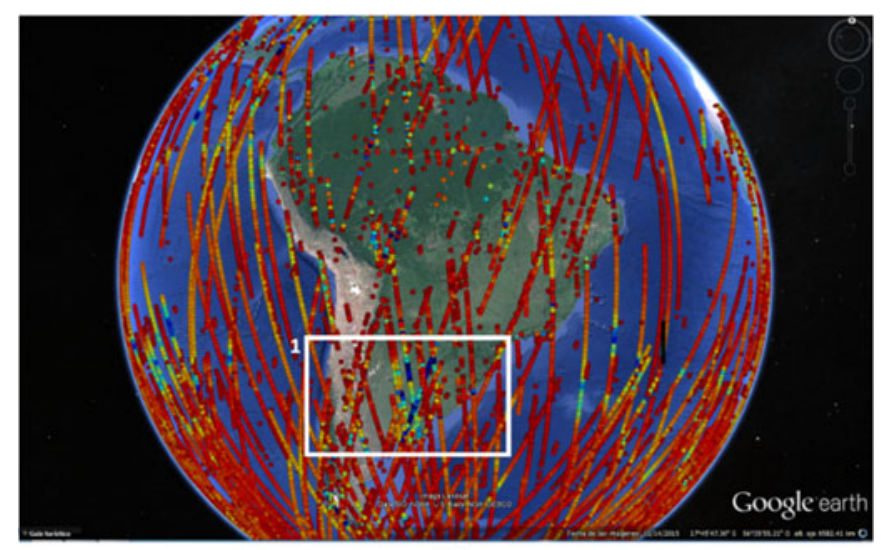

(a)

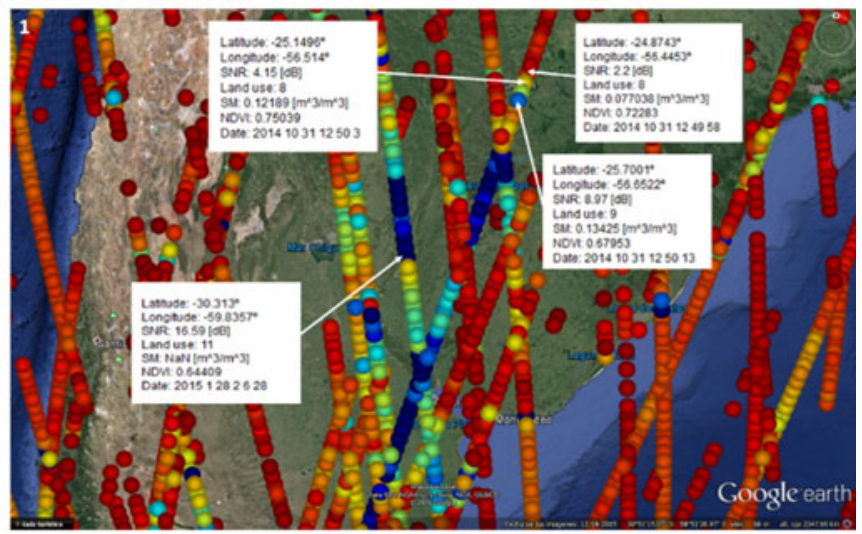

(b)

Fig. 8. Selected target areas over South America.

and, therefore, the lack of SM data automatically excludes these data points in this study.

It is important to note also that, despite the collocation efforts, the temporal and spatial resolutions of the different data are quite different, and this is probably one of the largest contributors to the scattering of the results presented in Section III, together with the footprint heterogeneity, surface topography, and surface roughness effects.

1) On one side, since the scattering of the GNSS signals over land is dominated by the coherent component [20] (see Fig. 6), the spatial resolution of the GNSS-R observations is given by the size of the first Fresnel zone $(\sim 1 \mathrm{~km}$, [10]), but blurred in the along-track direction due to the "long" incoherent averaging $\left(\sim v_{\text {ground-track }} \cdot T_{i} \approx\right.$ $6.5 \mathrm{~km} / \mathrm{s} \cdot 1 \mathrm{~s}=6.5 \mathrm{~km}$ ). Scattering over ice is even more coherent, and scattering over the ocean is mostly diffuse.

2) On the other side, the native resolution of SMOS SM data is $\sim 40-50 \mathrm{~km}$, although for convenience, level 3 data are regridded at $25 \mathrm{~km}$. The nominal SMOS temporal resolution is three days at the equator, but decreases with increasing latitude. In this study, both ascending and descending passes have been processed, but no noticeable differences have been found when using both datasets, therefore only the ascending passes are presented.

3) The different vegetation indices derived from MODIS are NDVI at $250 \mathrm{~m}$ at 16 day, and NDVI and enhanced 


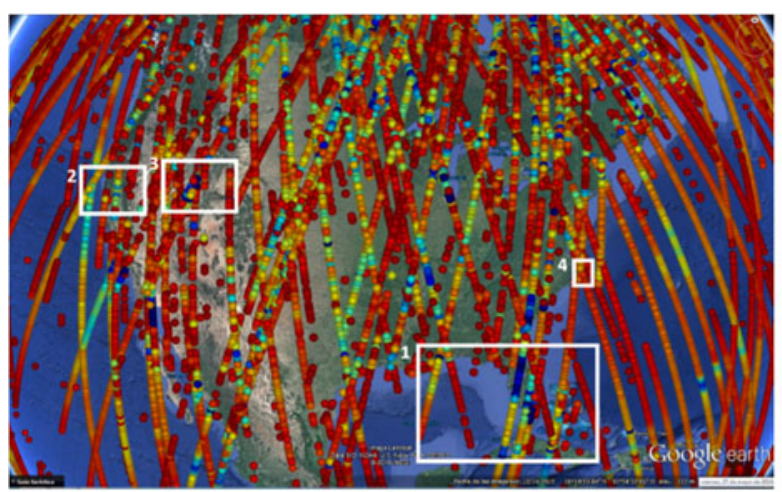

(a)

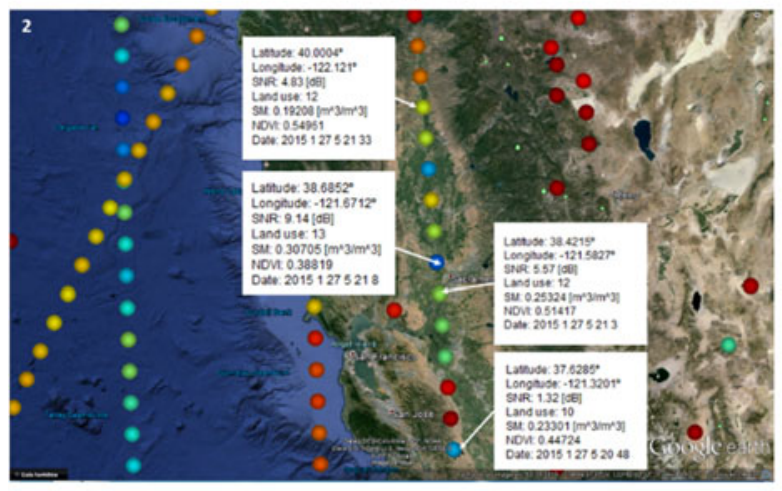

(c)

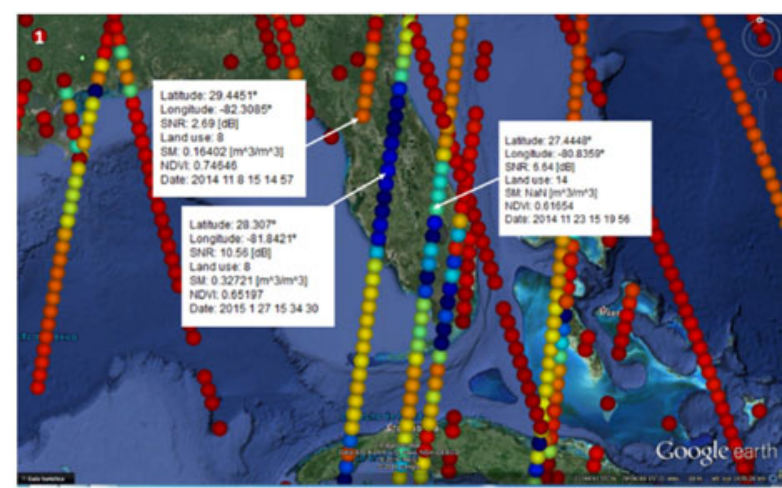

(b)

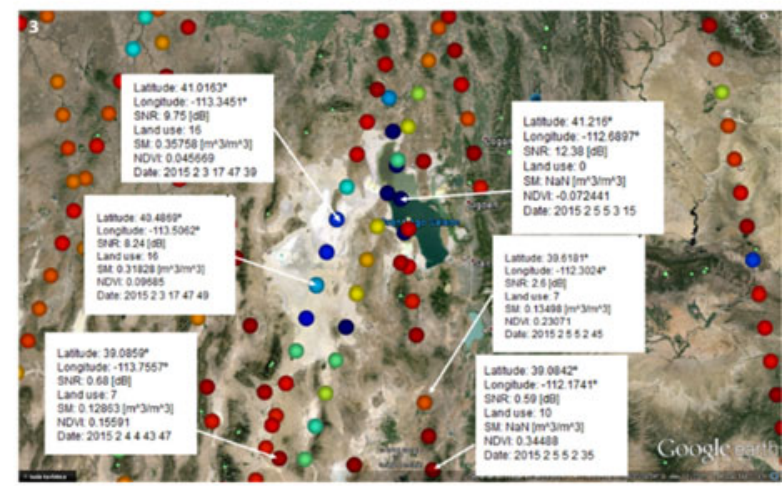

(d)

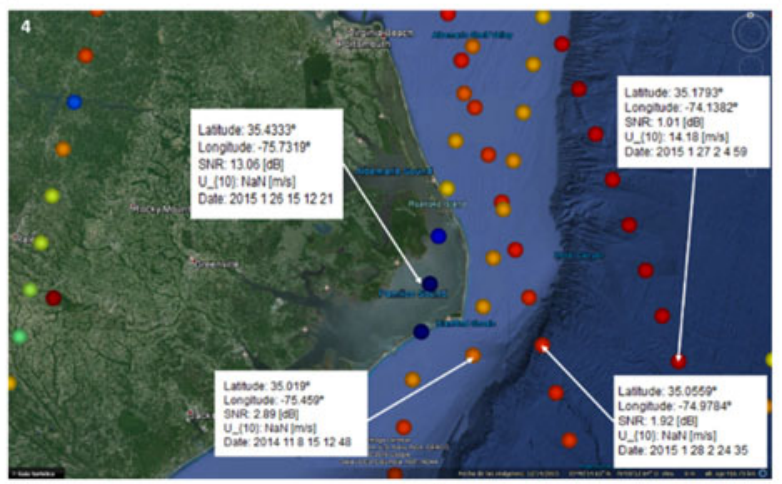

(e)

Fig. 9. Selected target areas over North America.

vegetation index at 1 and $25 \mathrm{~km}$ every 16 day or monthly. The ones available at [18] are regridded at an intermediate resolution of $0.1^{\circ}(\sim 10 \mathrm{~km}$ at the equator), and are produced every 16 days or monthly. The former ones (16 days) have been used.

4) Finally, the global land cover maps [19] derived from MODIS are the most recent ones, corresponding to 2011 and are regridded at a resolution of $0.1^{\circ}(\sim 10 \mathrm{~km}$ at the equator).

\section{UNDERSTANDING GNSS-R SPACEBORNE DATA}

In the following paragraphs, selected areas are presented to discuss different effects that are affecting the GNSS-R observations from space. In each target area, selected pixels are indicated showing the latitude, longitude, SNR, and date (year, month, day, UTC hour, minute, and second) of acquisition, and:

1) Over land: land use (according to classification in Fig. 4), SM value $\left[\mathrm{m}^{3} / \mathrm{m}^{3}\right]$ if retrieved, and NDVI [-], and

2) over water: $10-\mathrm{m}$ height ASCAT wind speed $\left[\mathrm{m} \cdot \mathrm{s}^{-1}\right]$, if retrieved (not too close to the coast).

Color scale (not shown) goes from 0 (red) to $20 \mathrm{~dB}$ (dark blue) and it is the same for all figures.

\section{A. Examples Over Australia}

Fig. 7 shows the whole map of Australia [see Fig. 7(a)], and two selected areas in Queensland, North of Brisbane [see Fig. 7(b)], and lakes Gairdner and Torrens, North of Adelaide [see Fig. 7(c)].

In Fig. 7(b), the two pixels on the East show quite high SM and NVDI values, and, therefore, high SNRs 


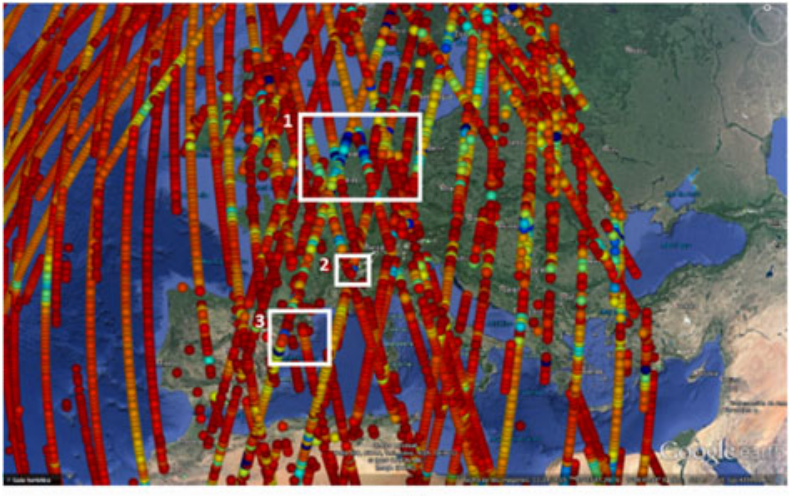

(a)

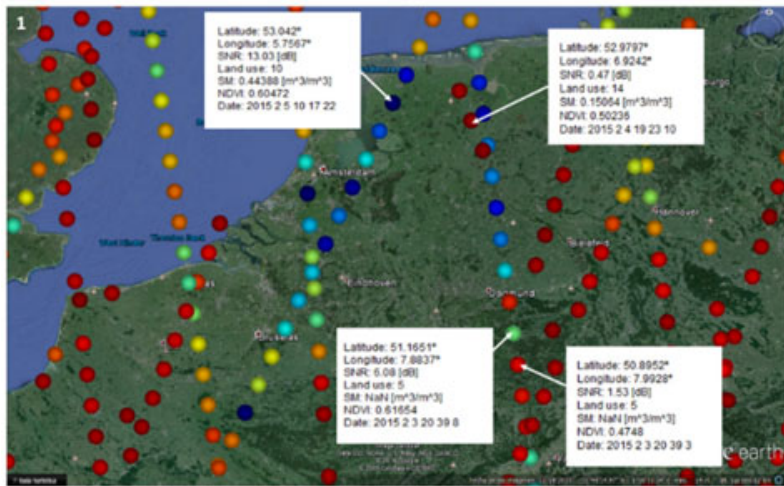

(b)

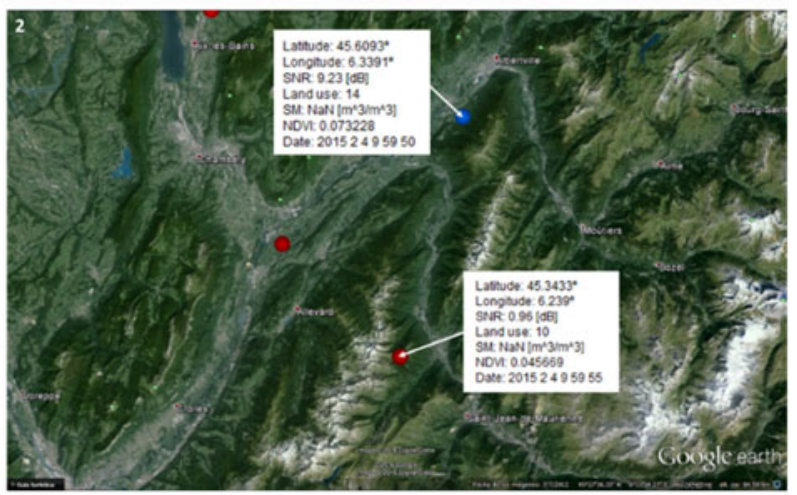

(c)

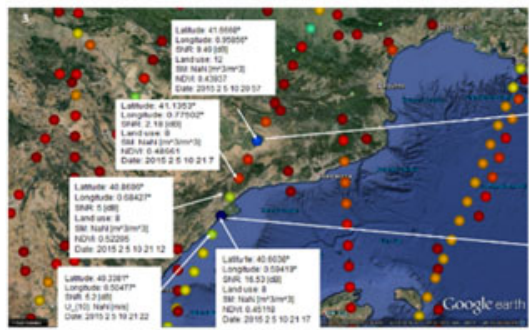

(d)

Fig. 10. Selected target areas over Europe.

(reflectivities). With decreasing SM and increasing NDVI, reflectivity decreases. However, the two pixels on the West show for the same land use (open shrubland) and very low SM values $(<0.05)$, very different SNRs $(>11 \mathrm{~dB})$, which is difficult to explain just because of the different NDVI values 0.21 and 0.37 (see Section IV-B).

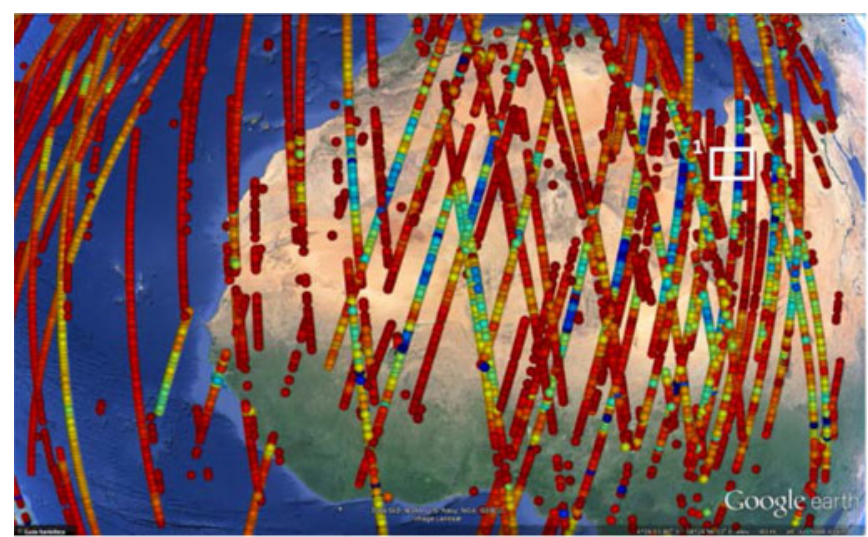

(a)

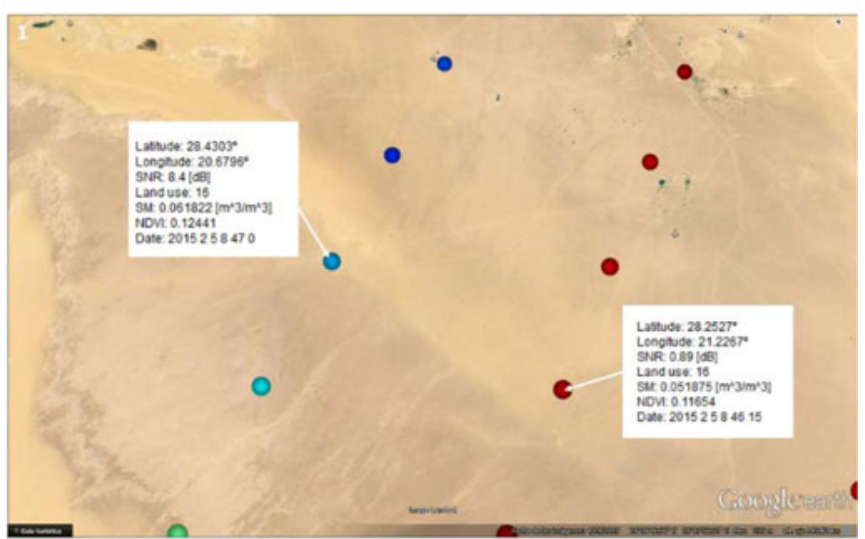

(b)

Fig. 11. Selected target areas over Africa.

The two pixels on the East in Fig. 7(c) are located in the shoreline of Island Lagoon, mostly a salt lake. The pixels encompass some land showing a low NDVI $(\sim 0.15)$ and low SM. The large difference in reflectivity here $(>13 \mathrm{~dB})$ can be due to the geometry since in the Easternmost pixels is in a mountainous region, while the central pixel is in a flat region, leading to a more specular reflection. The Western most pixel over Gairdner lake exhibits an intermediate value of SNR, the salty lake is nearly flat, and the SM value could not be derived from SMOS, most likely because the algorithm did not converge due to the salty nature of the terrain.

\section{B. Examples Over South America}

Fig. 8 shows the map of South America [see Fig. 8(a)], and a selected area East of Asunción, Paraguay encompassing woody savanna (class 8), and savanna (class 9). The three Northern most pixels exhibit very high NDVI values $(>0.68)$, but anomalous low SM values $(<0.13)$. A possible reason is that due to the dense vegetation cover, the accuracy of the SMOS retrieval algorithm degrades, and due to the large vegetation attenuation, the soil emission does not pass through it, and the estimated SM is lower than it should be. In any case, it is clear from these three pixels, that increasing NDVI (0.68 and 0.75$)$ leads to a reduction of the SNR (8.97 and $4.15 \mathrm{~dB}$, respectively), and that 


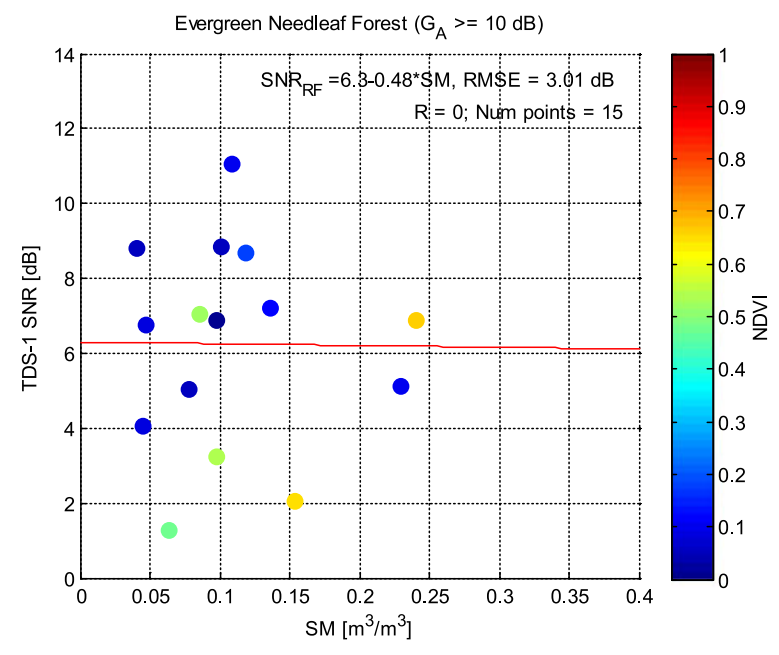

(a)

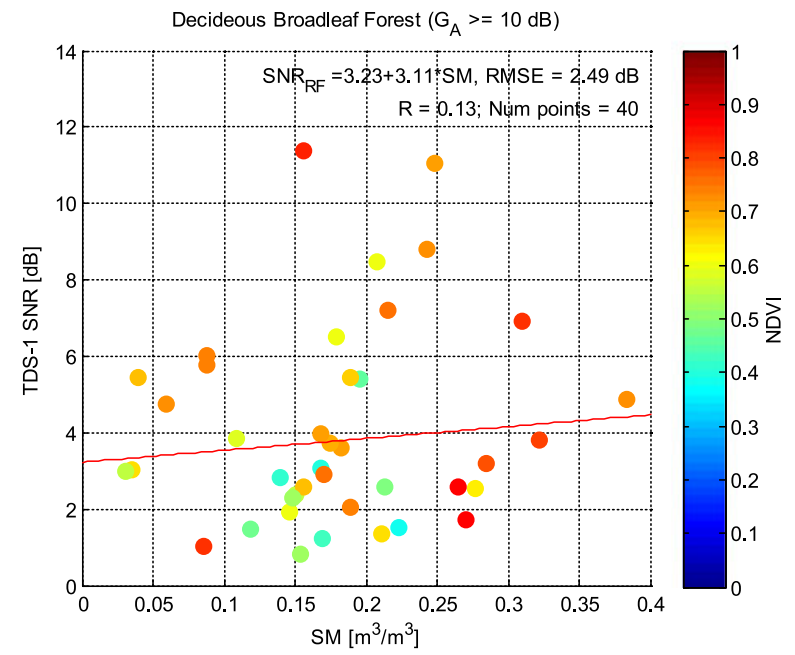

(c)

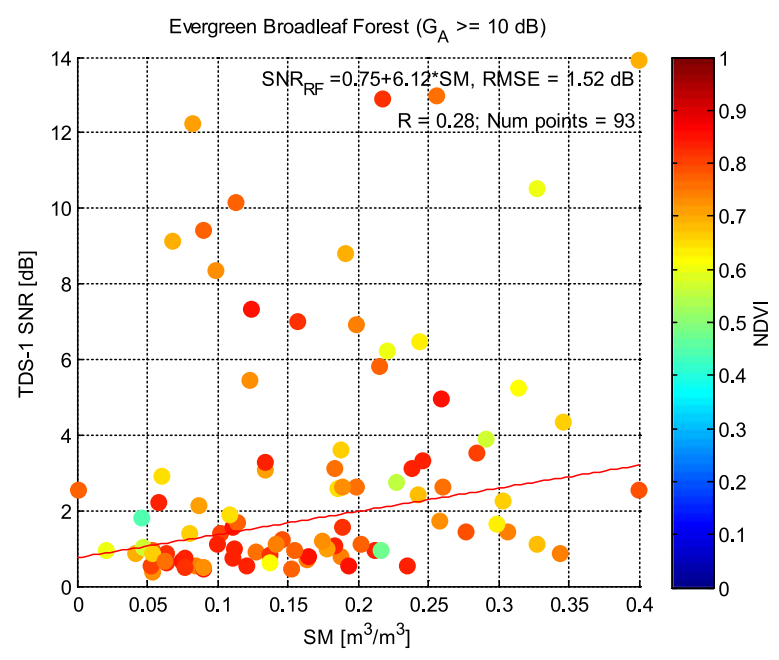

(b)

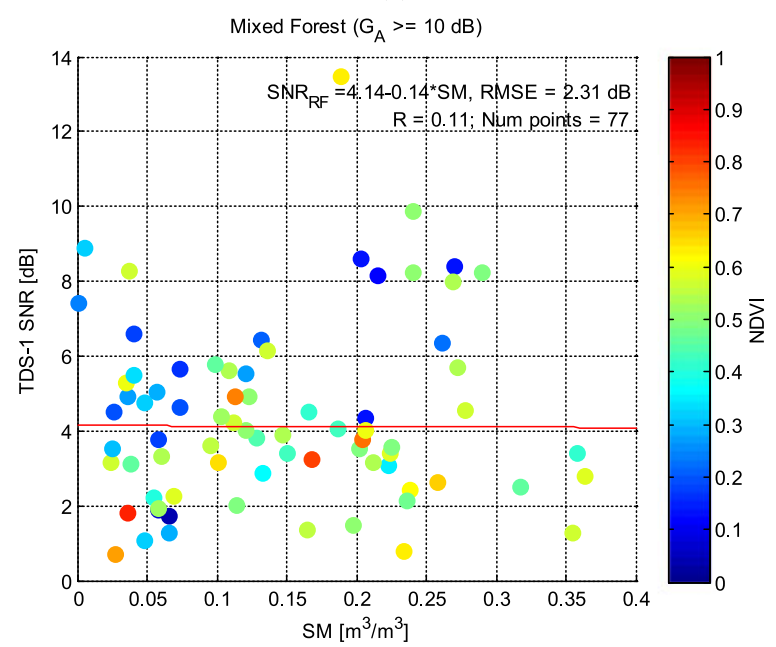

(d)

Fig. 12. Scatter plot and robust fit of TDS-1 GNSS-R data versus SMOS SM data for: (a) evergreen needleleaf forests, (b) evergreen broadleaf forests, (c) deciduous broadleaf forest, and (d) mixed forest.

decreasing SM (0.12 and 0.08) leads to a reduction of the SNR as well (4.15 and $2.2 \mathrm{~dB}$, respectively).

The Easternmost pixel corresponds to permanent wetlands (class 11), which leads to a high soil reflectivity, and despite the high vegetation cover (NDVI $=0.64)$ and attenuation, a high SNR (16.6 dB).

\section{Examples Over North America}

Fig. 9 shows the map of the US [see Fig. 9(a)], and four selected areas: the Florida peninsula [see Fig. 9(b)], San Francisco [see Fig. 9(c)], Salt Lake city [see Fig. 9(d)], and the Pamlico Sound [see Fig. 9(e)], in the North Carolina coast.

The Florida peninsula is a clear example of a flat terrain. The two Westernmost pixels correspond to "woody savanna," but the NDVI values are very high (0.65 and 0.75), and despite this, there is a significant sensitivity to SM changes $\sim 8 \mathrm{~dB}$ for a $0.16 \mathrm{~m}^{3} / \mathrm{m}^{3} \mathrm{SM}$ increase, which is significant, and clearly detectable with the TDS-1 antenna gain. The Easternmost pixel corresponds to cropland/natural vegetation, and it has also a very high NDVI value (0.62). The SM value has not been retrieved by SMOS, because the pixel is just about $\sim 25 \mathrm{~km}$ away from the Okeechobee Lake. However, in this case, due to the better spatial resolution (smaller footprint size), the signature on the GNSS-R observable is somewhere in between the other two pixels, which suggests that the SM can be retrieved at a better scale than with passive microwaves.

The San Francisco area has been selected because the satellite ground track passes through a mountainous region with land covers grassland for the Southernmost pixel, croplands for the Northernmost, and the third Northernmost pixels, and urban and built up for the second Northernmost pixel. Although the three rural pixels have a similar SM value $\left(0.19\right.$ to $\left.0.25 \mathrm{~m}^{3} / \mathrm{m}^{3}\right)$, the reflectivity does not follow a particular pattern. It does for the two cropland pixels, where the higher SM value is associated with a higher reflectivity, but it does not for the grassland pixel which exhibits a lower SNR (reflectivity), despite the lower NDVI, and a similar SM value. It is also surprising, because the terrain is nearly flat, so the GNSS reflection should be nearly specular, leading to a stronger return. 


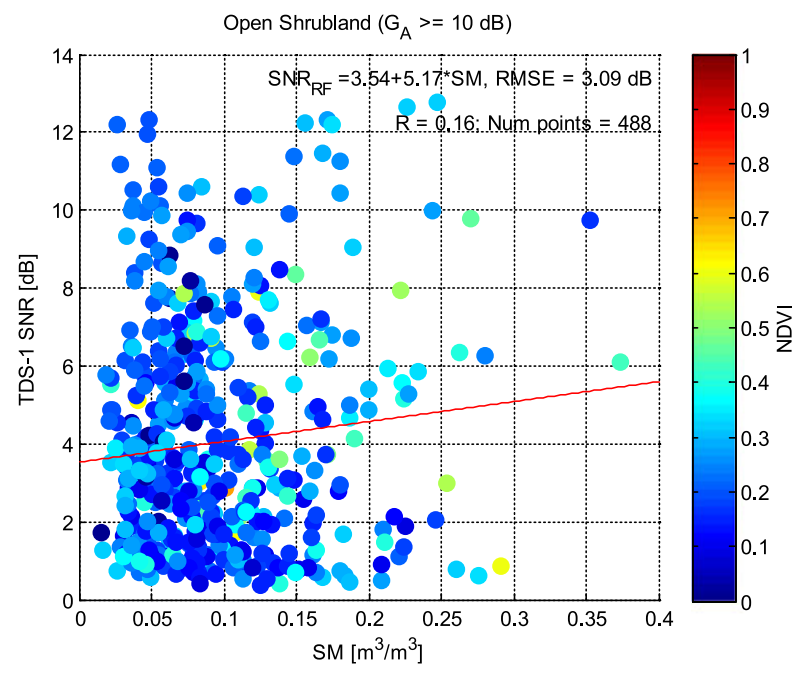

(a)

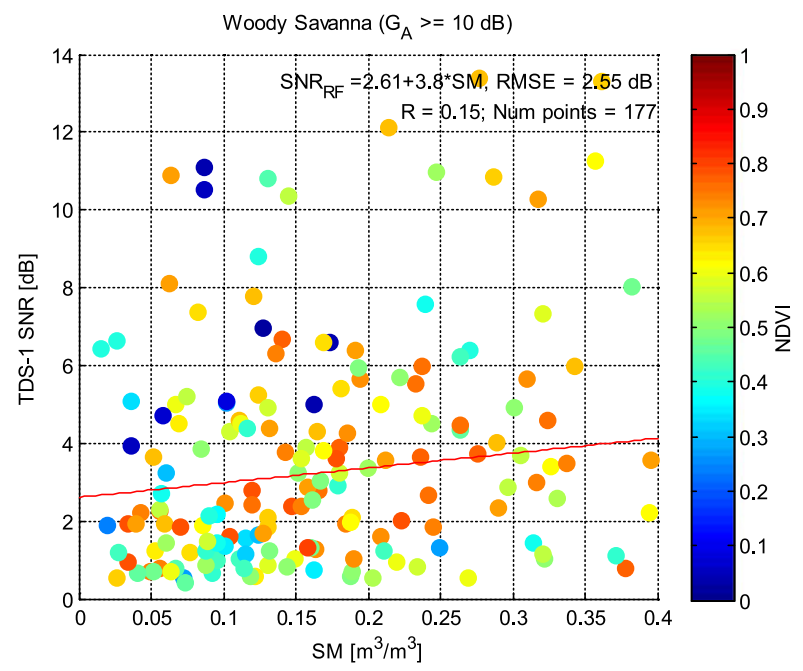

(c)

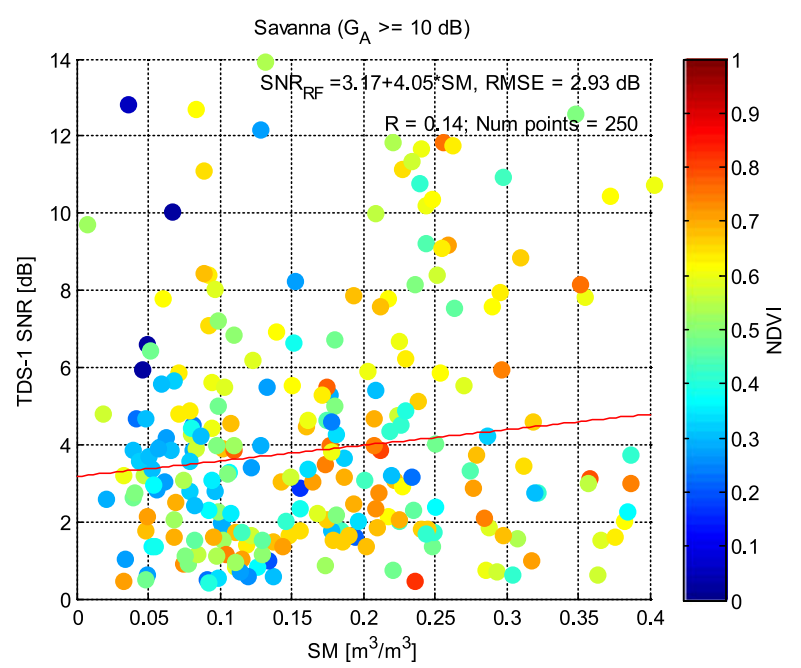

(b)

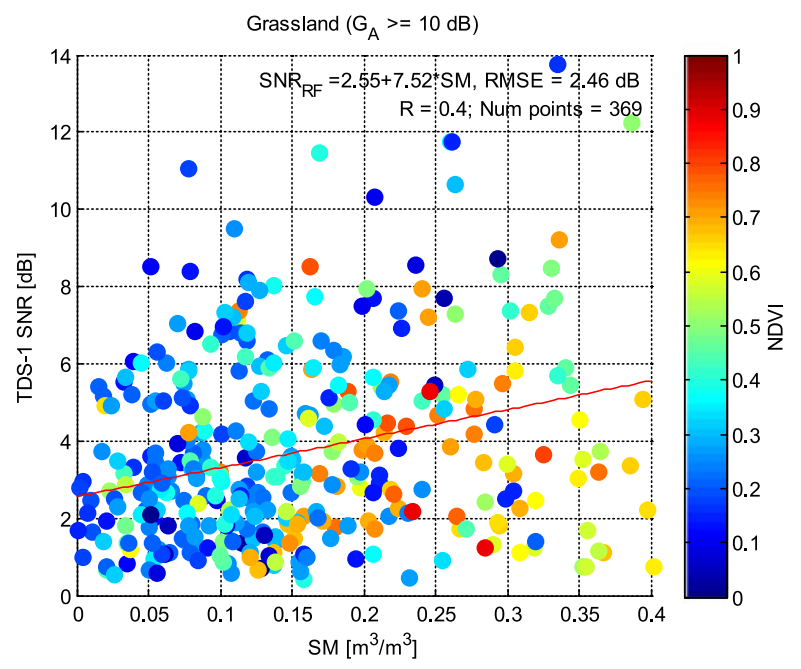

(d)

Fig. 13. Scatter plot and robust fit of TDS-1 GNSS-R data versus SMOS SM data for: (a) open shrublands, (b) savanna, (c) woody savanna, and (d) grasslands.

Six pixels in the Salt lake city region have been selected: the reflection in the North East pixel is the strongest one, since it corresponds to a reflection over calm water (SM is available, and NVDI is slightly negative). The next two pixels in the Eastern track correspond to open shrubland, and grassland, with increasing values of NDVI. However, in the second one, the SMOS SM value is not available because it is a mountainous region, which may also explain the lower ( $\sim 2 \mathrm{~dB}$ less) reflection coefficient. The three pixels on the Western most tracks correspond basically to flat areas with low vegetation. The first two in the North correspond to barren or sparsely vegetated areas (NDVI $<0.1$ ), with a relatively high SM (0.32 and 0.35), while the one in the South corresponds to open shrubland, it is drier, and it has a lower vegetation content. As expected, the SNR (reflectivity) for the first two pixels is therefore much higher $(\sim 7.5-9 \mathrm{~dB})$.

For the sake of completeness, the last region in the US in the North Carolina coast shows some results over the ocean: from a nearly specular reflection in calm waters of the Pamlico sound, with a strong coherent component $(\mathrm{SNR}=13.06 \mathrm{~dB})$, to an incoherent reflection over open waters, with decreasing SNRs down to $1.01 \mathrm{~dB}$ for the Easternmost pixel with moderate high winds $14.18 \mathrm{~m} / \mathrm{s}$. Note that wind speed values close to the coast cannot be retrieved.

\section{Examples Over Europe}

Three selected target areas over Europe have been selected (see Fig. 9): The Netherlands/West Germany [see Fig. 9(a)], the French Alps [see Fig. 9(b)], and Catalonia [see Fig. 9(c)] in the North East of Spain.

In The Netherlands/West Germany, the pixel in the North West is categorized as grassland, but a careful study shows that it corresponds to an inland water body (Sneekermeer), which explains the large reflectivity value. Despite this, since the surface fraction cover by water is relatively small, SMOS was able to infer a (high) SM value, and the NDVI also indicates the presence of dense vegetation. The two pixels in the South correspond to mixed forest, in a mountainous region (SM is not 


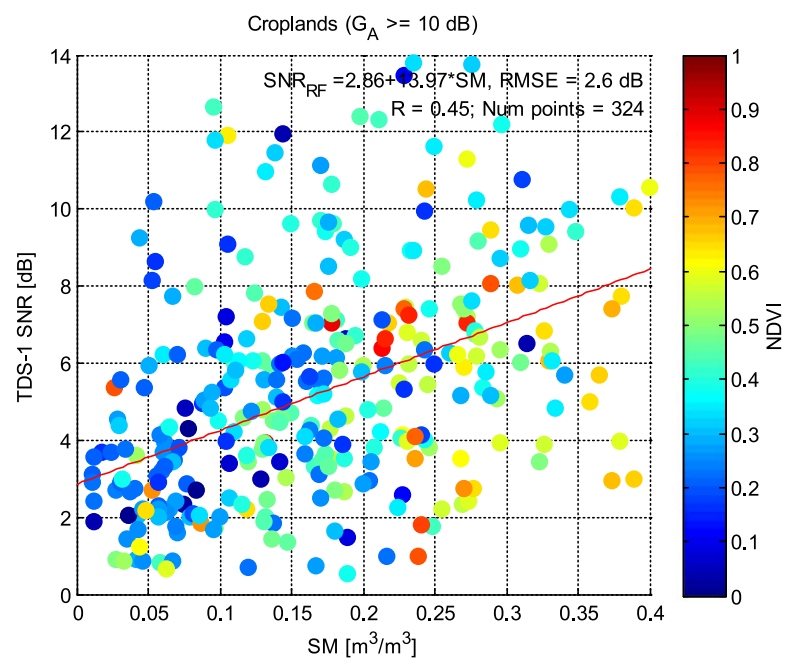

(a)

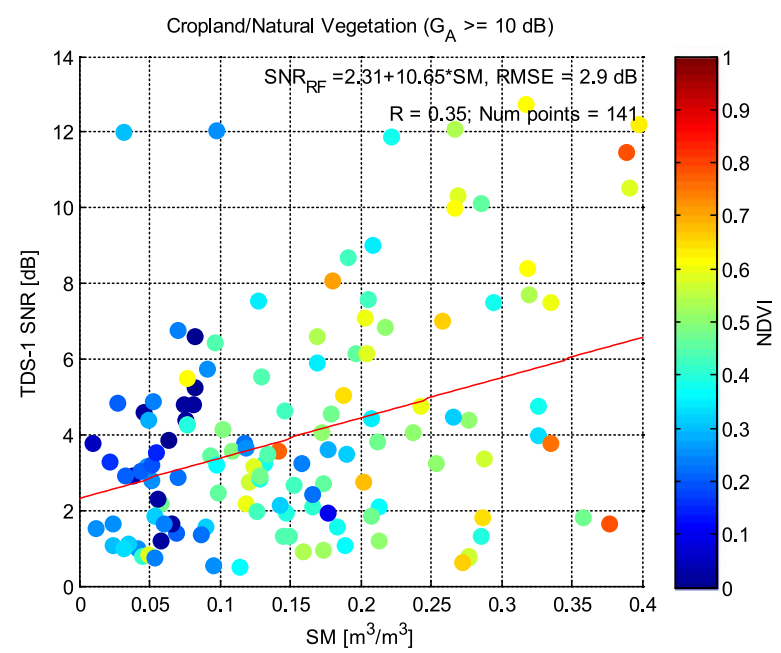

(b)

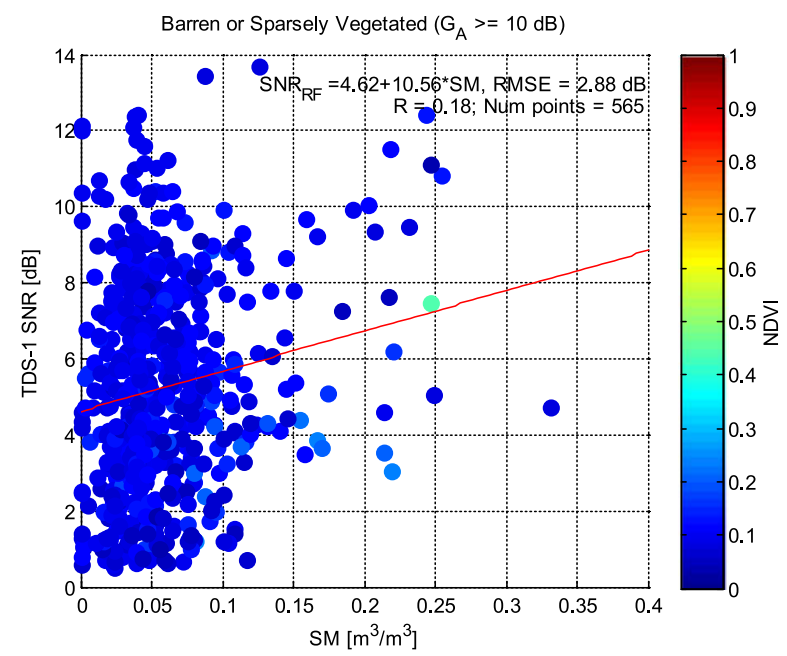

(c)

Fig. 14. Scatter plot and robust fit of TDS-1 GNSS-R data versus SMOS SM data for: (a) croplands, (b) croplands/natural vegetation, and (c) barren or sparsely vegetated regions. available), and with dense vegetation (NDVI from 0.48 to 0.62 ). Again, differences in the reflectivities here can only be attributed to differences in the SM values (not available) and on surface topography effects. The pixel in the North-East is categorized as cropland/natural vegetation, but a more detailed analysis reveals it is a flat cropland area with a high NDVI $=0.5$. In this pixel, the estimated $\mathrm{SM}$ value is lower than the others $(\mathrm{SM}=0.15)$, but the reflectivity is significantly lower $\sim 0.5 \mathrm{~dB}$, without an apparent explanation.

In the French Alps region, two pixels with very low vegetation (NDVI $<0.07$ ) have been selected to illustrate the effect of the topography slopes in the reflectivity. While in the Northern pixel the SNR is as high as $9.23 \mathrm{~dB}$, in the Sourthern one, it is just $0.96 \mathrm{~dB}$, because the different slopes, as compared to the satellite view. In the Northern pixel, the slope is looking in the North-West direction, while in the second case, the slope is looking South. SM is not available in both cases because of the topography effects, but it is not believed to be the main source of difference.

In the Catalonia region, five pixels in a ground track have been selected: from South to North, the first one is in the Mediterranean sea, but less than $10 \mathrm{~km}$ away from the coastline, so the ASCAT wind speed is not available. In this case, the SNR is $5.2 \mathrm{~dB}$, significantly lower than for the next pixel, which lies in the Alfacs bay at the South of the Ebro river mouth [see Fig. 10(d) lower right panel], where the water is very calm, and the reflection is nearly specular. In this case, the SNR is as high as $16.53 \mathrm{~dB}$, the highest one that has been found in the whole dataset. The next two pixels correspond to "woody savanna" and exhibit a decreasing SNRs because of the increasing topography effects, and the decreasing SM (SMOS SM is not available, but inspection of the land use shows olive trees in the first case and a variety of cereals in the second one). Finally, the Northernmost pixel has been selected because, despite the area is classified as croplands, the SNR is dominated by a specular reflection in the Ivars water reservoir [see Fig. 10(d) upper right panel]. Since this water reservoir is much smaller in size than other water bodies for which a high SNR is observed, it can be used to estimate the geolocalization errors, which are $\sim 2 \mathrm{~km}$, much smaller than the pixel size of the SMOS SM, and the MODIS land cover and NDVI maps used $\left(0.1^{\circ}\right.$ resolution).

\section{E. Examples Over Africa}

Over Africa [see Fig. 11(a)], two selected pixels in the Lybia's desert are shown [see Fig. 11(b)]. Both pixels belong to ground tracks correctly classified as barren or sparsely vegetated, with nearly zero SM, and very small NDVI $(<0.12)$, even though a smaller value would be expected. What is surprising is that, under apparently the same surface conditions, and no evident topography effects, both acquisitions, which are nearly simultaneous, exhibit very different SNRs ( 0.89 versus $8.4 \mathrm{~dB}$ ). No plausible reason has been found, except for a weak volume scattering and a soil dielectric profile inhomogeneity (i.e., the GNSS signals are reflected from an underground layer of higher dielectric constant), as suggested-for example-in [21] and [22]. 


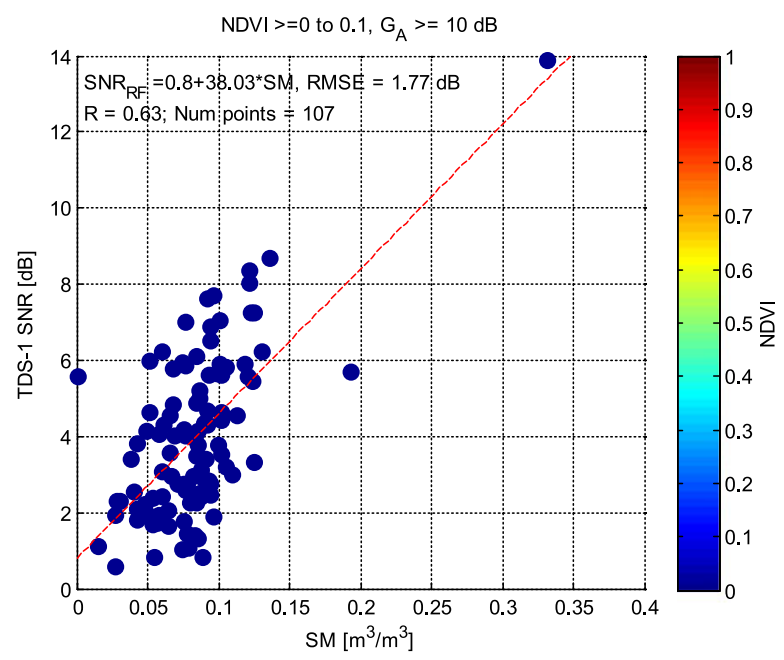

(a)

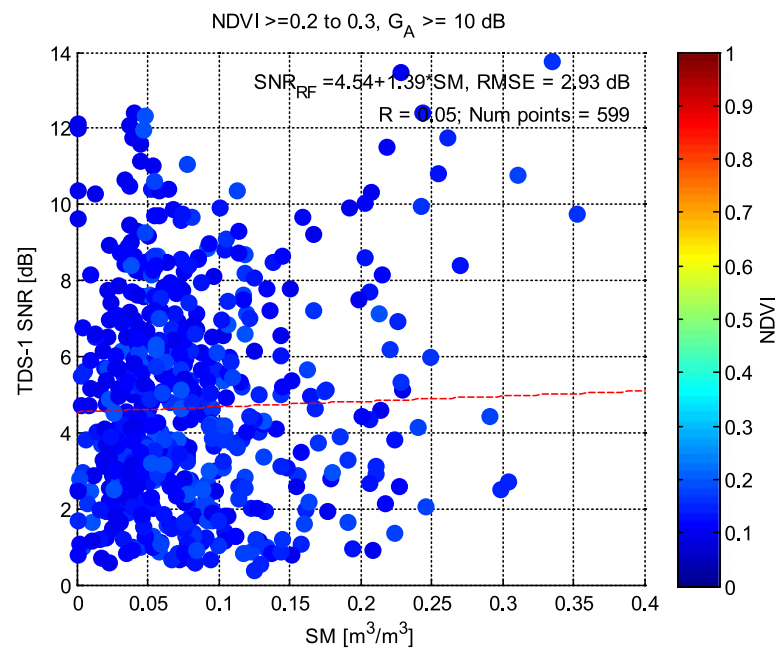

(c)

Fig. 15. Continued.

\section{RESUlTS AND DiscussiON}

From the total of 515540 GNSS-R data points, there are 125565 collocations with SM data, for which 7699 correspond to an antenna pattern larger than $10 \mathrm{~dB}$ and near nadir incidence angle $\left(\theta_{i} \leq 15^{\circ}\right)$. These data are analyzed first as a function of the surface type, and later as a function of the NDVI.

\section{A. Data Analysis as a Function of the Surface Type}

After preprocessing the datasets described above, the scatter plots of TDS-1 SNR versus SMOS SM are plotted for each surface type for which there was enough data in order to perform a robust fit [23], indicating the MODIS NDVI value with a color scale from 0 (blue) to 1 (red). Figs. 12-14 summarize these results. The legend in each plot indicates the linear robust fit [23] of the data $\left(\mathrm{SNR}_{\mathrm{TDS}-1}\right.$ versus $\left.\mathrm{SM}_{\mathrm{SMOS}}\right)$, the RMS error of the fit, the Pearson correlation coefficient $(R)$, and the number of points used in the fit.

Figs. 12(a)-(d) shows the results over different types of forests. Results for deciduous needleleaf forests are not shown

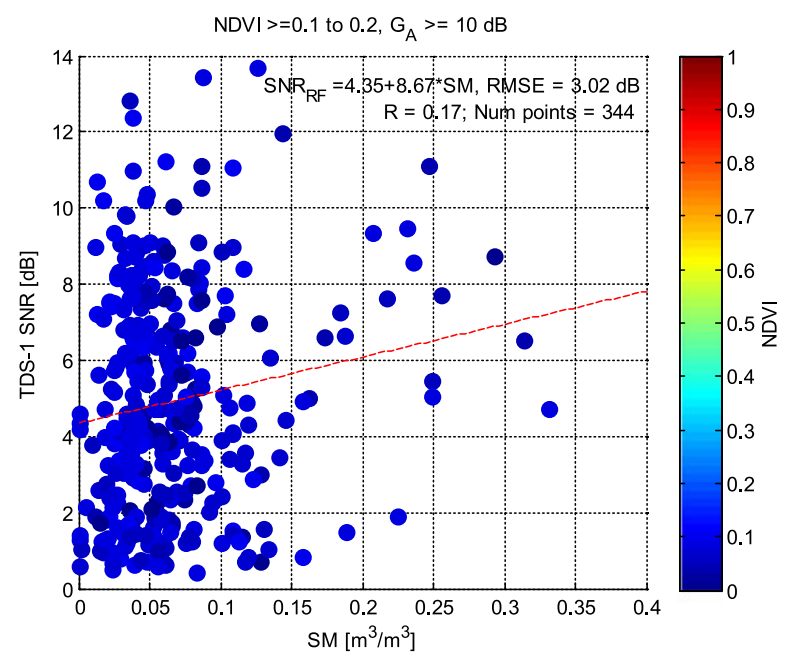

(b)

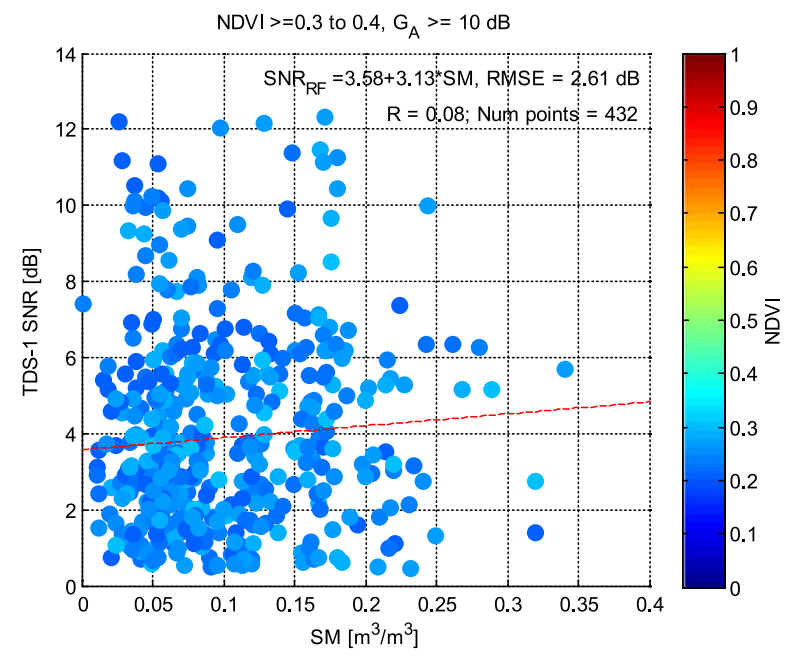

(d)

because of the lack of collocated data. Although there is no apparent sensitivity to SM in the case of needleleaf and mixed forests, in the case of broadleaf forests, there is some small sensitivity $\sim 3.1-6.1 \mathrm{~dB} /\left(\mathrm{m}^{3} / \mathrm{m}^{3}\right)$. However, it has to be noted that the Pearson correlation coefficient is quite low, even for evergreen broadleaf forests $(R=0.28)$. This can be attributed to the high NDVI values, and the footprint heterogeneity, except for the large extensions occupied by evergreen broadleaf forest in tropical regions.

Fig. 13(a)-(d) shows the results over open shrublands, savannas, woody savannas, and grasslands. Again, there is some sensitivity to the surface $\mathrm{SM} 3.8-7.5 \mathrm{~dB} /\left(\mathrm{m}^{3} / \mathrm{m}^{3}\right)$, actually larger than that over forests, although the Pearson correlation coefficient is still quite low, except for grasslands $(R=0.4)$. The scattering of the data is quite large, suggesting that footprint heterogeneity mainly, and topography to a smaller extent may be playing an important role (as illustrated in Section III). This is especially significant in the case of open shrublands, in which the NDVI values are low. The differences between savannas and woody savannas are not significant, and within the level of the scattering of the data. Grasslands exhibit the highest sensitivity 


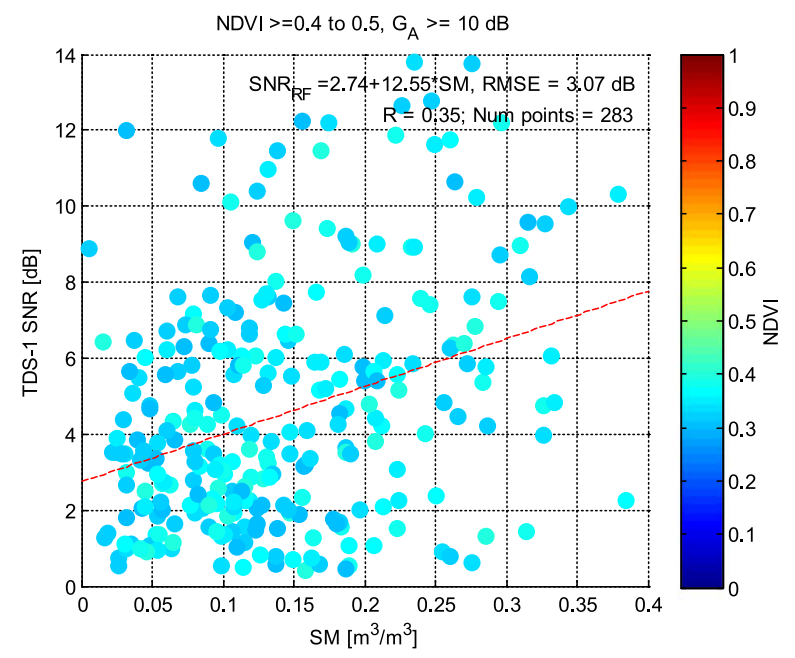

(e)

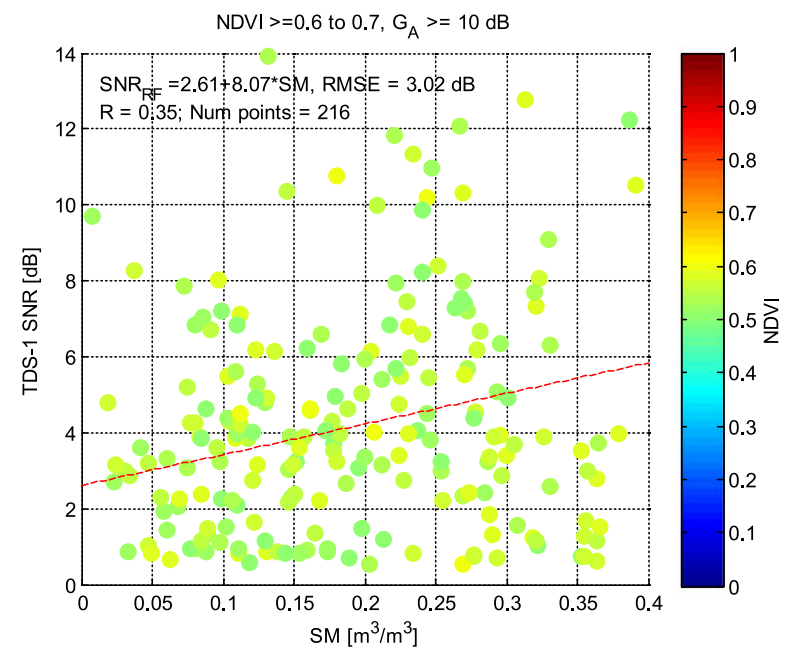

(g)

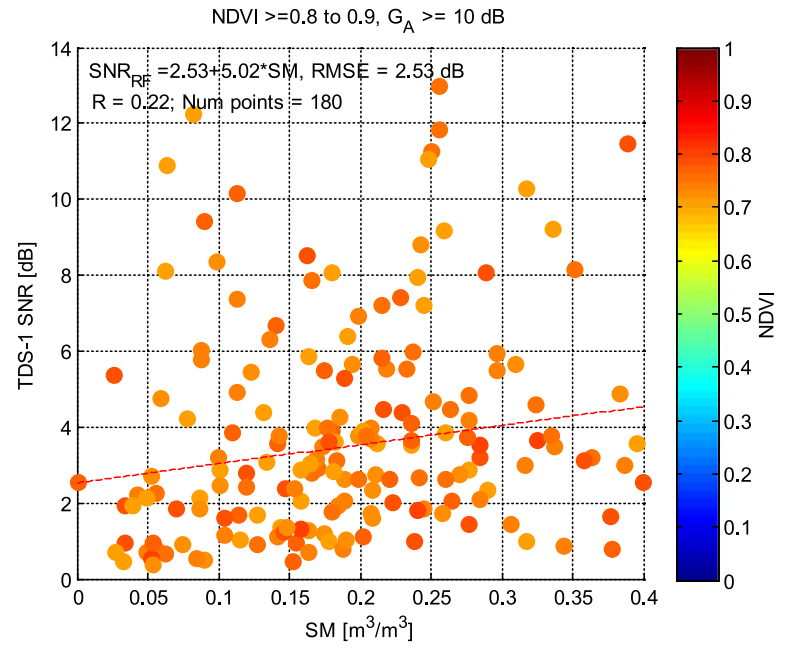

(i)

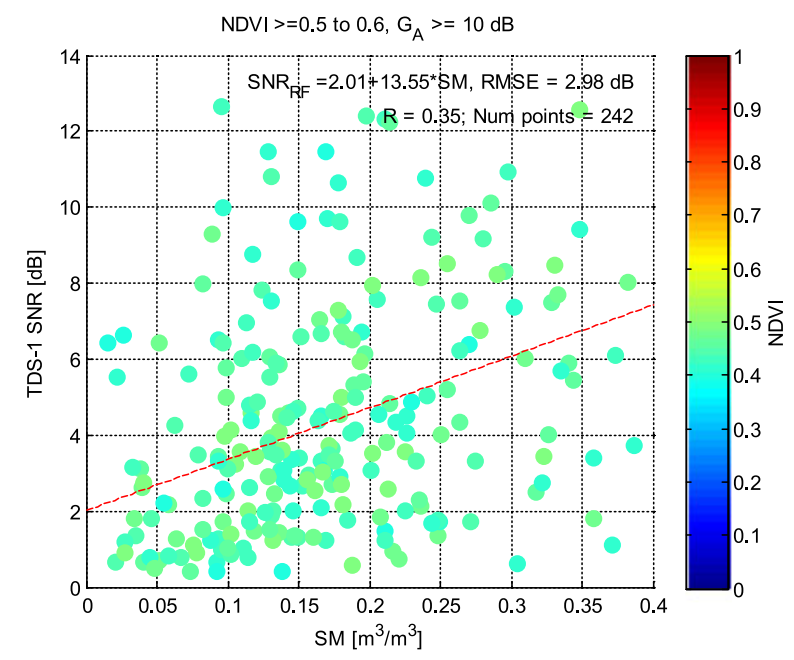

(f)

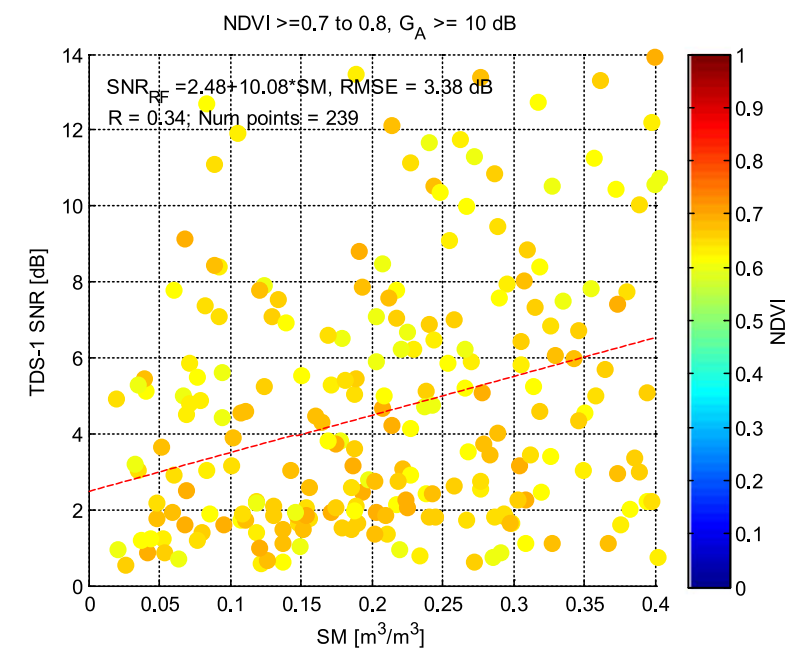

(h)

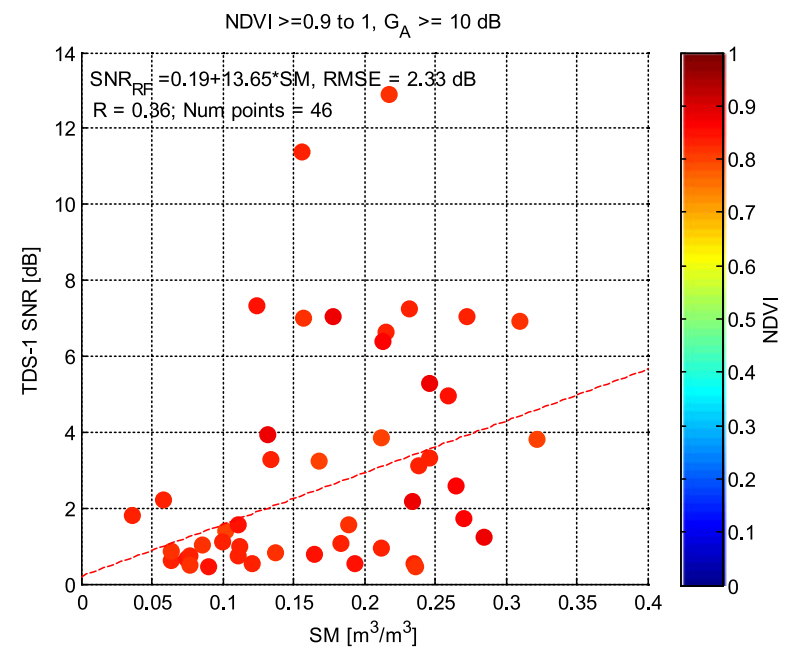

(j)

Fig. 15a. Scatter plot and robust fits of TDS-1 GNSS-R data versus SMOS SM data binned in NDVI ranges of 0.1. 


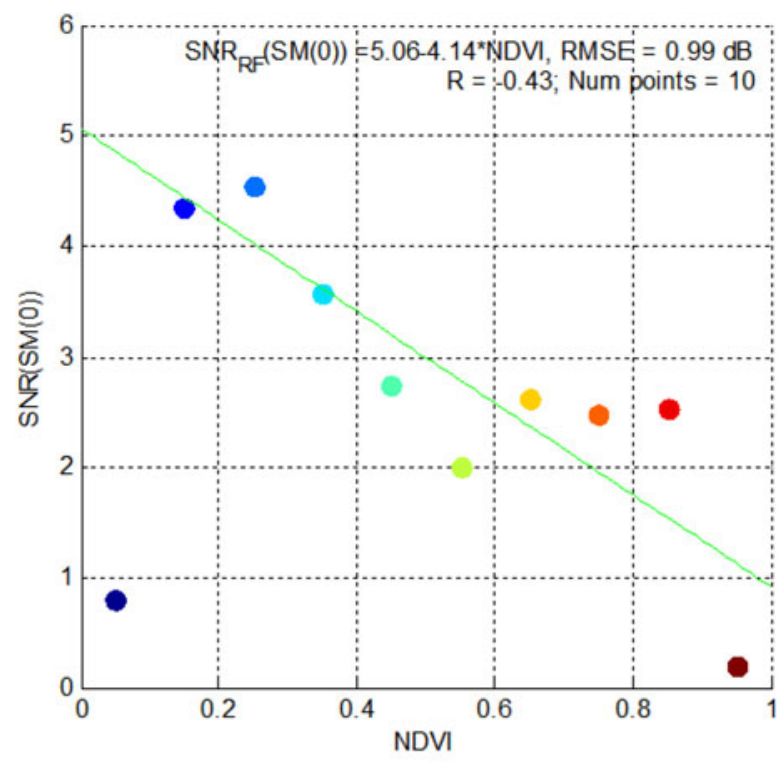

(a)

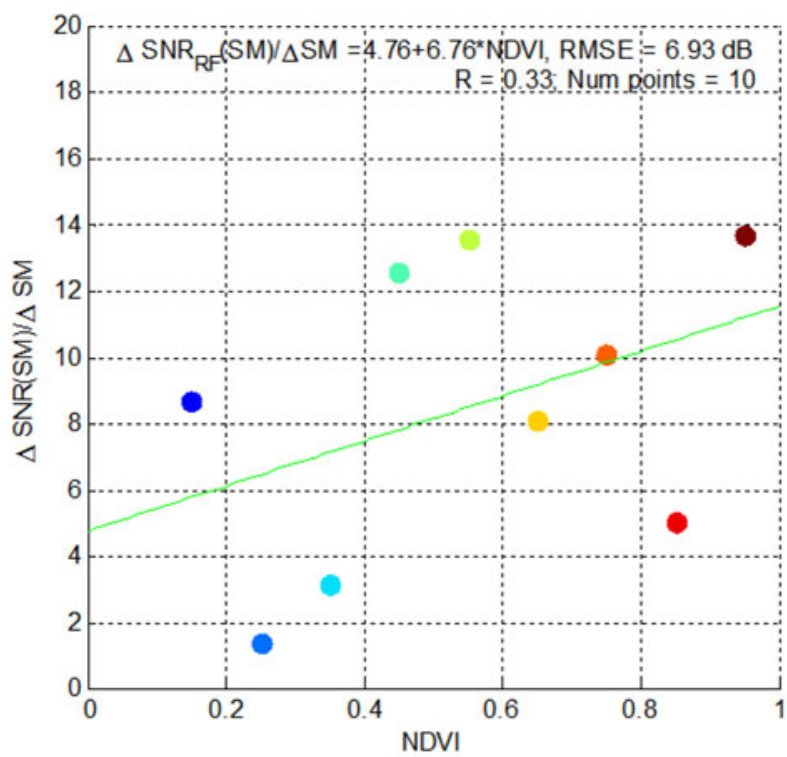

(b)

Fig. 16. Linear robust fits of (a) ordinates at the origin in $[\mathrm{dB}]$ and (b) slopes $\left[\mathrm{dB} /\left(\mathrm{m}^{3} / \mathrm{m}^{3}\right)\right]$ corresponding to Fig. $15(\mathrm{a})-(\mathrm{j})$.

to $\mathrm{SM} \sim 7.5 \mathrm{~dB} /\left(\mathrm{m}^{3} / \mathrm{m}^{3}\right)$, and the highest Pearson correlation coefficient, but the scatter plot reveals that the higher SM values correspond also to higher NDVI values, and most data points are lying below the regression line. This is an indication that the vegetation layer is attenuating the GPS signal, and, thus, it is reducing the sensitivity to soil moisture. This point will be addressed later.

Finally, Fig. 15(a) to (c) shows the results over croplands, croplands/natural vegetation areas, and barren/sparsely vegetated areas. Now, the sensitivity to the surface SM is the highest $10.7-14.0 \mathrm{~dB} /\left(\mathrm{m}^{3} / \mathrm{m}^{3}\right)$, as well as the Pearson correlation coefficient ( $R=0.45$ and 0.35 ), except for the barren/sparsely vegetated areas which is just $R=0.19$, despite the low NDVI values. This is an unexpected result that suggests that despite the apparent footprint homogeneity (see Fig. 4, class 16), other effects, such as topography (even gentle slopes) may be playing a role due to the variations of the local incidence angle, as discussed in [11] and [20].

\section{B. Data Analysis as a Function of the NDVI}

In the previous section, it has become apparent that the vegetation cover plays an important role reducing the sensitivity to soil moisture. In this study, the vegetation height has not been used as a proxy for vegetation because, from L-band microwave radiometry, it is known that it is the VWC what matters in the attenuation, which is the dominant effect at L-band, much larger than the scattering that takes place in the branches and trunks. Since the VWC can be related to the leaf area index (LAI), the NDVI, or other vegetation indices, the NDVI has been used since it is readily available every 15 days from NASA NEO website [18]. The impact of vegetation attenuation will be analyzed in more detail in Section IV-C.

To further analyze this effect, the whole dataset has now been binned by NDVI values in steps of 0.1 , regardless of the land use. Results are shown in Fig. 15(a)-(j). Fig. 15(a) corresponds to NDVI values from 0 to 0.1 . In this case, the absence of vegetation translates into a very high sensitivity to $\mathrm{SM} \sim 38 \mathrm{~dB} /\left(\mathrm{m}^{3} / \mathrm{m}^{3}\right)$, and the highest Pearson correlation parameter $R=0.63$, which demonstrates the large sensitivity of GNSS-R observations to soil moisture. As the NDVI increases $(0.1 \leq \mathrm{NDVI} \leq 0.4)$, vegetation reduces the sensitivity to soil moisture, and the Pearson correlation coefficient sharply decreases. This can be attributed to different factors, but notably to footprint heterogeneity, rather than to vegetation attenuation and scattering effects. Interestingly, for higher NDVI values $(0.4 \leq \mathrm{NDVI} \leq 1.0)$, the sensitivity to $\mathrm{SM}$ increases again $\left(5.0-13.6 \mathrm{~dB} /\left(\mathrm{m}^{3} / \mathrm{m}^{3}\right)\right)$, as well as the Pearson correlation coefficient $R \approx 0.22-0.35$. This apparently surprising result may be attributed to the fact that densely vegetated areas are also those for which there is more water availability for plants to grow.

Fig. 16 shows the linear robust fits of (a) the ordinates at the origin, and (b) the slopes corresponding to Fig. 15(a)-(j). The values of the ordinate at the origin and slope for NDVIs between 0 and 0.1 are both discarded by the robust fit as outliers. As for the other NDVI values, the linear robust fit predicts a decrease of the reflectivity (ordinate at the origin) from 5 to $1 \mathrm{~dB}$, and an increase of the slope from 5 to $12 \mathrm{~dB} /\left(\mathrm{m}^{3} / \mathrm{m}^{3}\right)$ when the NDVI increases from 0 to 1 , although in the second case, there is a large scattering in the data. The decrease of the reflectivity (ordinate at the origin) is associated to the reduction of the apparent reflection coefficient due to the presence of vegetation as it will be discussed in Section IV-C.

\section{Vegetation Impact on GNSS-R Observations}

At this point, it is worth noting that, since the scattering over the soil surface is mostly coherent, the prediction of the vegetation impact on the GNSS-R observations can benefit from the extensive studies performed for microwave radiometry at L-band, i.e., at $1.4 \mathrm{GHz}$, in which the Tau-Omega has been 
successfully used [24], [25]:

$$
\begin{aligned}
e_{p}= & \frac{1-\Gamma_{p}^{\text {bare, rough }}}{L_{p}^{\text {canopy }}}+\left[1-\frac{1}{L_{p}^{\text {canopy }}}\right] \cdot\left(1-\omega_{p}^{\text {canopy }}\right) \\
& +\frac{\Gamma_{p}^{\text {bare, rough }}}{L_{p}^{\text {canopy }}} \cdot\left[1-\frac{1}{L_{p}^{\text {canopy }}}\right] \cdot\left(1-\omega_{p}^{\text {canopy }}\right)
\end{aligned}
$$

where the first term corresponds to the soil emission attenuated by the vegetation canopy, the second one corresponds to the vegetation upwelling emission including the first-order scattering through the single scattering albedo ( $\left.\omega_{p}^{\text {canopy }}\right)$, and the third one to the vegetation downwelling emission reflected on the soil surface, and then attenuated and scattered in the vegetation in the upwelling path. The vegetation layer attenuation is $L_{p}^{\text {canopy }}=e^{\tau_{p}^{\text {canopy }}} / \cos (\theta)$, where $\tau_{p}^{\text {canopy }}$ is the nadir optical depth of the vegetation layer.

From the emissivity in (1), the soil+vegetation reflection ${ }^{3}$ coefficient can be derived as

$$
\Gamma_{p}^{\text {soil }+\operatorname{veg}}(\theta)=\Gamma_{p}^{\mathrm{soil}}(\theta) \cdot e^{-2 \cdot \tau_{p}^{\text {canopy }} / \cos (\theta)} \cdot\left(1-\omega_{p}^{\text {canopy }}\right)^{2}
$$

where $\Gamma_{p=L R}(\theta)=\left(\Gamma_{v}(\theta)-\Gamma_{h}(\theta)\right) / 2$ is the reflection coefficient at circular polarization expressed as a function of the vertical and horizontal linear polarization reflection coefficients [26], $2 \cdot \tau_{p}^{\text {canopy }}$ is the two-way vegetation opacity, and $\left(1-\omega_{p}^{\text {canopy }}\right)^{2}$ accounts for the two-path of the GPS signal in the down- and upwelling paths.

For low vegetation, the vegetation opacity (also known as vegetation optical depth) can be related to the VWC as [24], [25]:

$$
\tau_{p}=b \cdot \mathrm{VWC}=(0.12 \pm 0.03) \cdot \mathrm{VWC}
$$

and good correlation has also been obtained for green vegetation between $\tau_{p}$ and the LAI, although this parameterization is less accurate during the senescence phase, during which the opacity might be underestimated from low LAI values over some vegetation types. A possible parameterization is given by [24], [25]:

$$
\begin{aligned}
\tau_{\mathrm{NAD}} & =b_{s}^{\prime} \cdot \mathrm{LAI}+b_{s}^{\prime \prime} \\
\tau_{p} & =\tau_{\mathrm{NAD}} \cdot\left(\sin ^{2}(\theta) \cdot t t_{p}+\cos ^{2}(\theta)\right)
\end{aligned}
$$

where the $t t_{p}$ are parameters that allow to account for the dependence of $\tau_{p}$ with the incidence angle. Even though all vegetation parameters $b_{s}^{\prime}, t t_{h}$, and $t t_{v}$ are a function of the canopy type, the dependence of $b_{s}^{\prime}$ and on the canopy hydric status, and the change of the vegetation structure in relation to the phenology is usually neglected $\left(b_{s}^{\prime}=0.06, b_{s}^{\prime \prime}=0\right)$. The dependence of $\tau_{p}$ with the incidence angle and polarization can also be usually neglected $\left(t t_{h}=t t_{v}=1\right)$, so $\tau_{p}=\tau_{v}=\tau_{h}=\tau_{\mathrm{NAD}}$, and, therefore, $\tau_{L R}=\tau_{h, v}$. For low vegetation, at L-band, the single-scattering albedo can be safely neglected $\omega^{\text {canopy }} \approx 0$.

Forests are aggregated in three categories: needle leaf and broadleaf (including tropical forests and woodland), mixed

\footnotetext{
${ }^{3} \Gamma_{p=L R}$ stands for the reflection coefficient when the incident wave is righthand circularly polarized, as in the case of GNSS signals, and the scattered wave is left-hand circularly polarized.
}

forests, and woodlands. The same general procedure can be applied for the three categories as in the low vegetation case, although the parameters are specific of each category [25]:

$$
\tau_{\mathrm{NAD}}=b_{F}^{\prime} \cdot \mathrm{LAI}_{\max }+b_{F}^{\prime \prime}
$$

leading to a unified approach. As a result of the variability in orientation of branches and leaves, a simple $\tau_{\mathrm{NAD}}$ constant independent on the polarization and incidence angle is often used which includes the contributions from the crown, the litter, and the understory: $b_{F}^{\prime}=0.295$ for deciduous broadleaf, evergreen broadleaf, and woodlands, $b_{F}^{\prime}=0.337$ for needle leaf, and $b_{F}^{\prime}=0.31$ for mixed forests, and $b_{F}^{\prime \prime}=0$. For forests, the single scattering albedo may also be considered constant, i.e., independent on angle, polarization and time, but not negligible. At L-band, it is approximated by $\omega^{\text {canopy }} \approx 0.095$ for deciduous broadleaf, evergreen broadleaf, and woodlands, $\omega^{\text {canopy }} \approx 0.080$ for needle leaf, and $\omega^{\text {canopy }} \approx 0.087$ for mixed forests.

The application of the Tau-Omega model explains the different behaviors presented, but not the lack of sensitivity to of mixed and needleleaf forests.

In [27], a number of vegetation indices were analyzed to account for the vegetation effects in GNSS-R observations. It was concluded that the Normalized Difference Water Index 2 computed as NDWI2 - red $=\left(\rho_{\text {red }}-\rho_{\mathrm{SWIR} 2}\right) /\left(\rho_{\text {red }}+\rho_{\mathrm{SWIR} 2}\right)$ from bands red $(640-670 \mathrm{~nm})$, and SWIR2 (2100-2290 nm) from LANDSAT 8 Operational Land Imager instrument, was the most promising one. However, since it has been demonstrated [28] that a linear relationship exists between optical depth and $\log (1-\mathrm{NDVI})$ (with $R^{2}>99 \%$ ), in this study, among different vegetation indices, the NDVI has been used as a variable to account for the vegetation status.

\section{CONCLUSION}

A recent study [11] has analyzed the received GNSS-R power from TDS- 1 versus $\log (\sigma)$, being the $\sigma$ the rms surface height, the canopy height, the SMOS dielectric constant, and the SMOS retrieved soil moisture. In this study, a qualitative analysis of the surface soil moisture, roughness, topography, and subsurface volume scattering has been performed to illustrate and justify the impact of SM and vegetation in the GNSS-R data, and the scatter in the statistical results obtained later. Then, the sensitivity of GNSS-R scattered power to SM is analyzed at global scale over different types of surfaces, and for a wide range of values of the NDVI. It has been shown that for nearly bare soils, there is a high sensitivity to $\mathrm{SM} \sim 38 \mathrm{~dB} /\left(\mathrm{m}^{3} / \mathrm{m}^{3}\right)$, and a high Pearson correlation parameter $R=0.63$, in agreement with [11] where a sensitivity of $7 \mathrm{~dB} /\left(0.2 \mathrm{~m}^{3} / \mathrm{m}^{3}\right)$ was quoted. The reflection coefficient and the sensitivity to SM both decrease with increasing vegetation opacity (and scattering). However, excluding NDVI values smaller than 0.1 , there is a moderate increase of the sensitivity to SM for increasing NDVI, which may be attributed to the fact that the denser vegetation covers occur in humid regions. Since GNSS-R observations over land are mostly coherent, the impact of the vegetation cover can benefit from the parameterizations of the vegetation opacity and the single scattering 
albedo of the well-known Tau-Omega model successfully used in L-band microwave radiometry. Despite the vegetation cover reduces the GNSS-R reflectivity values and the sensitivity to soil moisture, vegetation effects can be accounted for in GNSSR SM retrieval algorithms using vegetation indices such as the NDVI, the LAI, or the SWIR2 [27] to compensate for vegetation effects in SM retrieval algorithms from space-borne GNSS-R.

\section{ACKNOWLEDGMENT}

This study has been performed in the frame of projects "Aplicaciones Avanzadas en Radio Ocultaciones y Dispersometría Utilizando Señales GNSS y otras Señales de Oportunidad," MINECO AYA2011-29183-C02-01, "E-GEM: European GNSS-R Environmental Monitoring," FP7-607126-EGEM, and "Técnicas Avanzadas en Teledetección Aplicada Usando Señales GNSS y Otras Señales de Oportunidad,” ESP201570014-C2-1-R from MINECO /FEDER.

\section{REFERENCES}

[1] C. D. Hall and R. A. Cordey, "Multistatic scatterometry," in Proc. Int. Geosci. Remote Sens. Symp., Moving Toward 21st Century, Sep. 12-16, 1988, vol. 1, pp. 561-562.

[2] J. C. Auber, A. Bibaut, and J. M. Rigal, "Characterization of multipath on land and sea at GPS frequencies," in Proc. 7th Int. Tech. Meet. Satellite Div. Inst. Navigat., 1994, pp. 1155-1171.

[3] M. Martín-Neira, "A passive reflectometry and interferometry system (PARIS): Application to ocean altimetry," ESA J., vol. 17, no. 4 pp. 331-355, 1993.

[4] S. J. Katzberg and J. L. Garrison, "Utilizing GPS to determine ionospheric delay over the ocean," NASA Tech. Memorandum, 4750, Dec. 1996.

[5] J. L. Garrison and S. J. Katzberg, "Detection of ocean reflected GPS signals: Theory and experiment," in Proc. IEEE Southeastcon Conf., Blacksburg, VA, USA, Apr. 1997, pp. 290-294.

[6] S. T. Lowe, J. L. LaBrecque, C. Zuffada, L. J. Romans, L. E. Young, and G. A. Hajj, "First spaceborne observation of an earth-reflected GPS signal," Radio. Sci., vol. 37, no. 1, pp. 7-1-7-28, 2002. [Online]. Available: http://onlinelibrary.wiley.com/doi/10.1029/2000RS002539/full, doi:10.1029/2000RS002539.

[7] S. Gleason et al., "Detection and Processing of bistatically reflected GPS signals from low Earth orbit for the purpose of ocean remote sensing," IEEE Trans. Geosci. Remote Sens., vol. 43, no. 6, pp. 1229-1241, Jun. 2005.

[8] TechDemoSat-1. (2016, Jan. 4). [Online]. Available: https://directory. eoportal.org/web/eoportal/satellite-missions/t/techdemosat-1

[9] The SGR-ReSI Space GNSS Instrument. (2016, Jan. 4). [Online]. Available: http://www.sstl.co.uk/Products/Subsystems/Navigation/SGR-ReSI

[10] V. U. Zavorotny, S. Gleason, E. Cardellach, and A. Camps, "Tutorial on remote sensing using GNSS bistatic radar of opportunity, "IEEE Geosci. Remote Sens. Mag., vol. 2, no. 4, pp. 8-45, Dec. 2014.
[11] A. Alonso-Arroyo et al., "Dual-polarization GNSS-R interference pattern technique for soil moisture mapping," IEEE J. Sel. Topics Appl. Earth Obs. Remote Sens., vol. 7, no. 5, pp. 1533-1544, May 2014.

[12] A. Egido et al., "Airborne GNSS-R polarimetric measurements for soil moisture and above-ground biomass estimation," IEEE J. Sel. Topics Appl. Earth Obs. Remote Sens., vol. 7, no. 5, pp. 1522-1532, May 2014.

[13] E. Motte et al., "GLORI: A GNSS-R dual polarization airborne instrument for land surface monitoring," Sensors, vol. 16, no. 5, p. 732, May 2016.

[14] C. Chew, R. Shah, C. Zuffada, G. Hajj, D. Masters, and A. J. Mannucci, "Demonstrating soil moisture remote sensing with observations from the UK TechDemoSat-1 satellite mission," Geophys. Res. Lett., vol. 43, pp. 3317-3324, 2016, doi:10.1002/2016GL068189.

[15] G. Foti et al., "Spaceborne GNSS reflectometry for ocean winds: First results from the UK TechDemoSat-1 mission," Geophys. Res. Lett., vol. 42, pp. 5435-5441, 2015.

[16] A. Camps, H. Park, G. Foti, and C. Gommenginger, "Ionospheric effects in GNSS-reflectometry from space," IEEE J. Sel. Topics Appl. Remote Sens., to be published.

[17] (2016, Jan. 4). CP34-BEC: SMOS-BEC data distribution and visualization services. [Online]. Available: http://cp34-bec.cmima.csic.es/

[18] Vegetation Index [NDVI]. (2016, Mar. 25). [Online]. Available: http://neo.sci.gsfc.nasa.gov/

[19] Land Cover Classification (1 year). (2016, Mar. 25). [Online]. Available: http://neo.sci.gsfc.nasa.gov/view.php?datasetId=MCD12C1_T1

[20] H. Carreno-Luengo, A. Camps, J. Querol, and G. Forte, "First results of a GNSS-R experiment from a stratospheric balloon over boreal forests," IEEE Trans. Geosci. Remote Sens., vol. 54, no. 5, pp. 2652-2663, May 2016.

[21] J. Du, J. S. Kimball, and M. Moghaddam, "Theoretical modeling and analysis of 1- and p-band radar backscatter sensitivity to soil active layer dielectric variations," Remote Sens., vol. 7, pp. 9450-9472, 2015.

[22] S. Zwieback, S. Hensley, and I. Hajnsek, "Assessment of soil moisture effects on L-band radar interferometry," Remote Sens. Environ., vol. 164, pp. 77-89, 2015.

[23] P. W. Holland and R. E. Welsch, "Robust regression using iteratively reweighted least-squares," Commun. Stat. Theory Methods, vol. 6 , pp. 813-827, 1977.

[24] Y. H. Kerr et al., "The SMOS soil moisture retrieval algorithm," IEEE Trans. Geosci. Remote Sens., vol. 50, no. 5, pp. 1384-1403, May 2012.

[25] (2016, Mar. 25). Array Systems Computing Inc., Algorithm Theoretical Basis Document (ATBD) for the SMOS Level 2 Soil Moisture Processor Development Continuation Project, ref SO-TN-ARR-L2PP-0037. Issue: 3.3. [Online]. Available: https://earth.esa.int/pub/ESA_DOC/SOTN-ARR-L2PP-0037_ATBD_v3_3.pdf

[26] V. U. Zavorotny and A. G. Voronovich, "Scattering of GPS signals from the ocean with wind remote sensing application," IEEE Trans. Geosci. Remote Sens., vol. 38, no. 2, pp. 951-964, Mar. 2000.

[27] N. Sánchez et al., "On the synergy of airborne GNSS-R and landsat 8 for soil moisture estimation," Remote Sens., vol. 7, pp. 9954-9974, 2015.

[28] E. J. Burke, W. J. Shuttleworth, and A. N. French, "Using vegetation indices for soil-moisture retrievals from passive microwave radiometry," Hydrol. Earth Syst. Sci., vol. 5, no. 4, pp. 671-677, 2001. 